\section{EMBRYRIDDLE \\ Aeronautical University}

SCHOLARLY COMMONS
International Journal of Aviation, Aeronautics, and Aerospace

\title{
Comparison of Flow field in the proximity of A Single Planar \& Wrap-around Fin
}

\author{
Nayhel Sharma \\ Punjab Engineering College, nayhel.sharma@gmail.com \\ Palak Saini \\ Punjab Engineering College, saini121@uwindsor.ca \\ Hrishabh Chaudhary \\ Punjab Engineering College, hrishabh.chaudhary@cranfield.ac.uk \\ Gurteg Nagi \\ Punjab Engineering College, g.nagi@cranfield.ac.uk \\ Rakesh Kumar Dr. \\ Punjab Engineering College, rakeshkumar@pec.ac.in
}

Follow this and additional works at: https://commons.erau.edu/ijaaa

Part of the Aerodynamics and Fluid Mechanics Commons, Applied Mechanics Commons, and the Other Aerospace Engineering Commons

\section{Scholarly Commons Citation}

Sharma, N., Saini, P., Chaudhary, H., Nagi, G., \& Kumar, R. (2019). Comparison of Flow field in the proximity of A Single Planar \& Wrap-around Fin. International Journal of Aviation, Aeronautics, and Aerospace, 6(4). https://doi.org/10.15394/ijaaa.2019.1393

This Concept Paper is brought to you for free and open access by the Journals at Scholarly Commons. It has been accepted for inclusion in International Journal of Aviation, Aeronautics, and Aerospace by an authorized administrator of Scholarly Commons. For more information, please contact commons@erau.edu. 


\section{INTRODUCTION}

Wrap-around fins (WAFs) are an unconventional control surface which envelope the cylindrical missile body. Chosen for their packaging convenience, these stabilizers can be folded in the stowed position to fit within a circular cylinder and deployed instantly after launch. Prior to these, the conventional planar fins were the preferred choice for stabilizing and control surfaces. Missiles having any of these stabilizing surfaces are often tail-controlled. The use WAF in the weapons industry is becoming more relevant for the tubelaunched missiles. Besides having superiority over the conventional planar fins in terms of storage, these fins also exhibit reduced drag at higher angle of attacks and operational stability. With the advancements in missile technology, there is an increasing demand for better fin performance. The design optimization and removal of anomalies associated with either of these fins has been a critical area of research. The WAF show a conventional longitudinal aerodynamic characteristic like that of planar fins of identical planform area.

Comparisons between the planar and wrap-around fins have been performed extensively in the past using both experimental and the numerical methods. Zhang, Ji, Xu, and Schlüte (2015) used a Spalart-Allmaras turbulence model to compare the aerodynamic characteristics between planar and wraparound fins by varying geometric parameters at supersonic speeds. Liu, Tang, and Guo (2013) performed simulations on the planar and wrap-around fin missiles and compared the basic aerodynamic characteristics between the two. Tanrõkulu, Onen, and Gokhan (2000) compared non-linear dynamic aerodynamic characteristics of a basic planar and wrap-around fin missile. The difference between the transverse aerodynamics of both the missile configurations were highlighted in their paper. A study of comparison to experimental results was undertaken by Washington (1983), in which the investigation of the rolling moment around the planar and wrap-around fins at supersonic speed was performed. Mandić (2006) analysed the rolling moments of wrap-around finned missile, by comparing a planar finned missile at a canted angle. He proved that at zero-degree angle of attack, the sum of rolling moment coefficient due to the curvature of the fin is equal to that of a canted planar fin. Though most of the comparisons have been performed at supersonic speeds, Lucero (1976) compared the subsonic stability and control characteristics of missiles having planar and wrap-around fins, whereas Dahlke (1976) compared and tested planar and wrap-around finned missiles having fins of the same projected area in the Mach number range of $\sim 0.3 \mathrm{M}-3.0 \mathrm{M}$ in a wind tunnel. The fin drag comparison, between the planar and the wrap-around, showed that the WAFs had $10 \%$ higher value as that of the planar fins. In the past, numerous numerical studies (Bagheri, Pasandidehfard, \& Tavakoli Sabour 2018; Li, Abbas, \& Rui, 2015; Krishna, Surit, Kushari, \& Ghosh, 2009; Eidell, Nance, McGowan, Carpenter, \& Moore, 2012; Murman, 2007) have been performed on planar and wrap-around finned missiles which have used inviscid, viscid and

turbulent flow conditions. However, most of these studies were performed on a 
complete missile body with four fins, these studies form the basis of implying turbulence modelling to the current model. The objective of this paper is to compare a single fin missile model in a wide range of Mach number and the motivation to do so is that, flow variations around fins (both planar and WAFs) of various shapes and sizes could be preliminarily analysed using a single fin model. This would save computational time and cost in investigating flow aerodynamics of newly shaped fins of a complete four-finned missile.

In the present study, viscid turbulent flow simulations were performed on a single fin, of planar and wrap-around type in a Mach number range of 0.43.0M. At each Mach number the angle of attack remained zero degrees. The current model and its geometry is based on the experimental and numerical studies performed by Tilmann (Huffman, Tilmann, Butler, \& Bowersoz, 1996; Tilmann, Huffman, Buter, \& Bowersox, 1996/1997; Tilmann, Buter, \& Bowersox, 1998). In these studies, the mean flow and turbulence measurements were quantified using pressure probes and hot-film anemometry. The wall mounted semi-cylindrical missile model had the fin proportions as that of aero ballistic models tested at the Wright Laboratory Armament Directorate (Vitale $\&$ Abate, 1992). The characterization of flow around a single fin was performed numerically at Freestream Mach numbers $\sim 2.8,2.9 \mathrm{M}$. These numerical studies utilized Baldwin and Lomax model of turbulence (Baldwin, Lomax, \& Ames, n.d.). The Baldwin and Lomax algebraic model solved the transonic flow without considering the edge of the boundary layer, shock formations and separation flow over a compression corner of an aerofoil. Also, the flow considered in the numerical analysis was inviscid. The shock structures, surface pressures and surface stream lines were computed, and their prediction was compared to the shadowgraph and Schlieren photography of the same model attached to the top surface of a test section in a wind tunnel.

The current computational analysis is accomplished by simulating a similar non-spinning single WAF as well as a single planar fin of same geometric area, at $0^{\circ}$ angle of attack in the freestream Mach number range of $0.4 \mathrm{M}$ to $3.0 \mathrm{M}$ at normal air conditions. The flow behaviour consisting of shock/boundary interaction and mean turbulence flow field is compared for both the fins. A two-equation $\mathrm{K}-\varepsilon$ turbulent model is utilized, and a second order of discretization is employed for all flow and turbulence parameters in the case of WAFs, however for the planar fins, due to their symmetric nature, second order discretization is applied for the turbulence parameters and first order discretization is applied for the flow parameters. Finally, after examining and comparing the two cases, for validation of the results, the computed values are compared with both existing experimental and computational studies. Best possible turbulence model was selected on the basis of previous computational researches (Sharma \& Kumar, 2019). 


\section{NUMERICAL METHODOLOGY}

\section{The Pre-Processing and The Mathematical Approach}

The present CFD analysis has been performed on the FLUENT module of ANSYS ${ }^{\circledR}$ software. The turbulence closure was carried out with the twoequation $\kappa-\epsilon$ turbulence model. This section provides the governing equations used in the present computations. The fundamental governing equations remain the continuity equation, the momentum equation and the energy equation.

Continuity equation: $\frac{\partial \rho}{\partial \mathrm{t}}+\nabla \cdot(\rho \mathrm{V})=0$

Momentum equation: $\rho \frac{\mathrm{DV}}{\mathrm{Dt}}=\nabla \cdot \boldsymbol{\tau}_{\mathbf{i j}}-\nabla \mathrm{p}+\rho \mathbf{F}$

Energy equation: $\rho \frac{D e}{D t}+\rho(\nabla \cdot \boldsymbol{V})=\frac{\partial Q}{\partial t}-\nabla \cdot \boldsymbol{q}+\boldsymbol{\Phi}$

The general transport equations for mass, momentum, energy etc. which are solved on a set of control volumes are,

$\frac{\partial}{\partial t} \int_{V} \rho \phi d V+\oint_{A} \rho \phi \boldsymbol{V} \cdot d \boldsymbol{A}=\oint_{A} \Gamma_{\phi} \nabla \phi \cdot d \boldsymbol{A}+\int_{V} S_{\phi} d \boldsymbol{V}$

where $\boldsymbol{\rho}$ is the fluid density, $\boldsymbol{V}$ is the fluid velocity vector, $\boldsymbol{\tau}_{\boldsymbol{i j}}$ is the viscous stress tensor, $\boldsymbol{p}$ is pressure, $\boldsymbol{F}$ is the body forces, $\boldsymbol{e}$ is the internal energy, $\boldsymbol{Q}$ is the heat source term, $\boldsymbol{t}$ is time, $\boldsymbol{\Phi}$ is the dissipation term, and $\boldsymbol{\nabla} . \boldsymbol{q}$ is the heat loss by conduction. Fourier's law for heat transfer by conduction can be used to describe $\boldsymbol{q}$ as:

$\boldsymbol{q}=-k \nabla T$

where $\boldsymbol{k}$ is the coefficient of thermal conductivity, and $\boldsymbol{T}$ is the temperature (Liu, 2014).

A time steady density based coupled solver with absolute velocity formulation was used to solve mass, momentum and energy species. The energy equation (Equation 3 ) is a requirement for the compressible high-speed flow as it captures the shock pattern effectively.

Three dimensional Navier-Stokes equations are utilized. Equations 6-8 represent viscous tensor by stokes hypothesis, these are expressed as follows:

$$
\begin{aligned}
& \frac{\partial \rho}{\partial t}+\frac{\partial}{\partial x_{j}}\left(\rho u_{j}\right)=0 \\
& \frac{\partial}{\partial t}\left(\rho u_{j}\right)+\frac{\partial}{\partial x_{j}}\left(\rho u_{j} u_{i}\right)=-\frac{\partial p}{\partial t}+\frac{\partial \hat{\tau}_{j i}}{\partial x_{j}} \\
& \frac{\partial}{\partial t}(\rho E)+\frac{\partial}{\partial x_{j}}\left(\rho u_{j} H\right)=\frac{\partial}{\partial x_{j}}\left[u_{i} \hat{\tau}_{j i}+\left(\mu+\sigma * \mu_{T}\right) \frac{\partial k}{\partial x_{j}}-q_{j}\right]
\end{aligned}
$$


Where $\boldsymbol{t}$ is the time, $\boldsymbol{x}_{\boldsymbol{i}}$ the position vector, $\boldsymbol{\rho}$ the density, $\boldsymbol{u}_{\boldsymbol{i}}$ the velocity vector, $\boldsymbol{p}$ the pressure, $\boldsymbol{\mu}$ the dynamic viscosity. The total energy and enthalpy are $\boldsymbol{E}=e+k+u_{i} u_{j} / 2$ and $\boldsymbol{H}=e+p / \rho+k+u_{i} u_{j} / 2$, respectively, with $\boldsymbol{e}=p /[(\gamma$ -1) $\rho$ ]. The $\gamma$ is the ratio of specific heats at constant pressure and constant volume. Other quantities are defined in the equations below:

$$
\begin{aligned}
\tau_{i j} & =2 \mu_{T}\left(S_{i j}-\frac{1}{3} \frac{\partial \mu_{k}}{\partial x_{k}} \delta_{i j}\right)-\frac{2}{3} \rho k \delta_{i j} \\
S_{i j} & =\frac{1}{2}\left(\frac{\partial u_{i}}{\partial x_{j}}+\frac{\partial u_{j}}{\partial x_{i}}\right)
\end{aligned}
$$

using Boussinesq hypothesis,

$$
\begin{aligned}
& \mu_{T}=\rho v_{t} \\
& \hat{\tau}_{i j}=2 \mu\left(S_{i j}-\frac{1}{3} \frac{\partial u_{k}}{\partial x_{k}} \delta_{i j}\right)+\tau_{i j} \\
& q_{j}=-\left(\frac{\mu}{p_{T_{L}}}+\frac{\mu_{T}}{p_{T_{T}}}\right) \frac{\partial h}{\partial x_{j}} \\
& k=\frac{1}{2} \mu_{j}^{\prime} \mu_{i}^{\prime}
\end{aligned}
$$

where $\boldsymbol{\delta}_{\boldsymbol{i}}$ indicates the Kronecker delta, and $\boldsymbol{\mu}_{\boldsymbol{i}}$, is the fluctuation of the velocity component $\boldsymbol{u}_{i}$.

A time steady density based coupled solver with absolute velocity formulation was used to solve mass momentum, energy species. For the formulation of turbulent viscosity, the turbulent Prandtl numbers governing the turbulent diffusion $\kappa \& \epsilon$ and the generation \& destruction terms in the $\epsilon$ equation, the two-equation realizable $\kappa-\epsilon$ was utilized. The term "realizable" means that the model satisfies certain mathematical constraints on the Reynolds stresses, consistent with the physics of turbulent flows (ANSYS, 2001a). The realizable $\kappa-\epsilon$ out performs the standard $\kappa-\epsilon$ model in terms of capturing freestream turbulence and other flow features. The non-equilibrium wall condition was used to accommodate the pressure gradient effects in the flow. Non-equilibrium because Reynolds number is greater than $10 e^{6}$ and $\mathrm{Y}$ plus is greater than 30 .

Air was considered to be an ideal-gas with constant parameters and Sutherland's three coefficient model (Sutherland, 2011) was applied for viscosity calculations. Pressure-far-field conditions were adopted for inlet and outlet. The missile-fin assembly was imparted a no slip wall condition. An implicit solution formulation, and Advection Upstream Splitting Method (AUSM) was used for flux solution (Li et al., 2015). The second-order accuracy was selected, in which the quantities at cell faces are computed using a multidimensional linear reconstruction approach. In this approach, higher-order accuracy is achieved at cell faces through a Taylor series expansion of the cell- 
centred solution about the cell centroid (ANSYS, 2001b). Finally, a strict convergence criterion ( $e^{-4}$ ) was met and the model was validated which has been presented in the following sections.

\section{Geometry}

The planar and the wrap-around fin were made of similar cross-section area and were placed on top of a semi-cylindrical body, which was shaped as a missile. The semi-cylindrical body was designed to represent a full missile of dimensions as mentioned in the reference (Tilmann et al., 1997) and the wraparound fins had the same dimensions as that of the models of the, Wright Laboratory Armament Directorate (Vitale \& Abate, 1992). The Figures 1 (a)(b) and 3 show the solid missile models. The Figures 2, 4, and 5 explain the dimensions of the planar missile model and the wrap-around fin models respectively. It has a total length of $10.92 \mathrm{r}$, where $\mathrm{r}=0.0159 \mathrm{~m}$ is the radius of curvature of the missile fin. Within this $5 \mathrm{r}$ length, a flat surface is blended to a $1 / 3$-cylinder section in such a way as to ensure second-order continuity in the longitudinal direction. This semi-cylindrical body has a length of 5.12r and a maximum height of $0.038 \mathrm{~m}$. The thickness of the rectangular shaped both leading and trailing edge blunt fin was kept at $0.00254 \mathrm{~m}$.

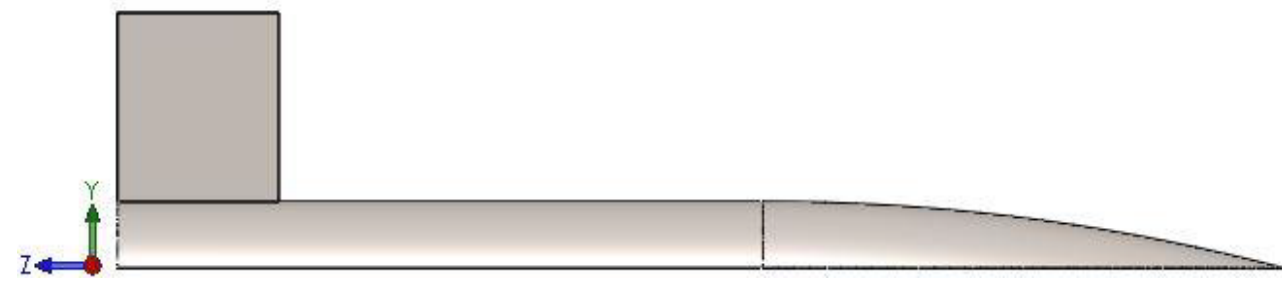

(a)

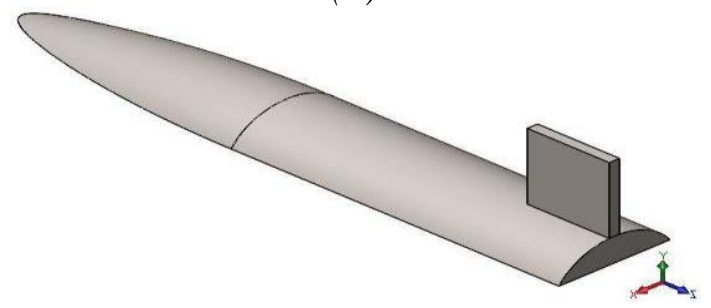

(b)

Figure 1(a)(b). 3-D Planar Single Fin Test Model (Solid). 

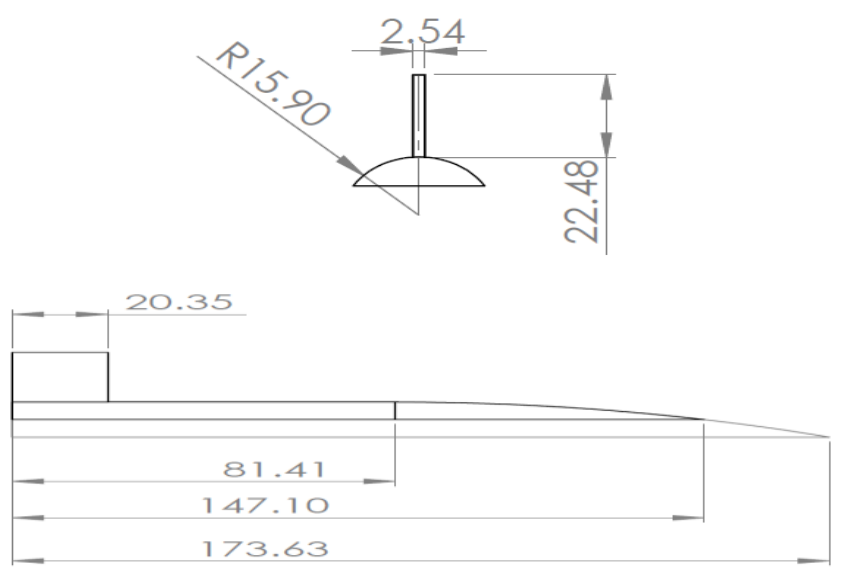

Figure 2. Detailed Planar Test Model dimensions in mm.

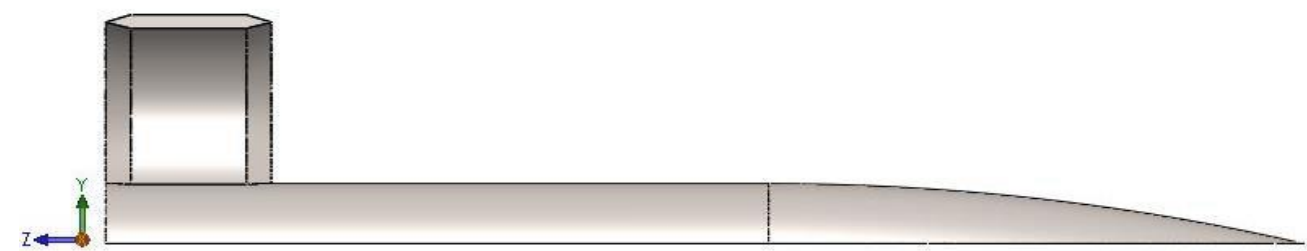

Figure 3. Single Fin Semi-cylindrical wrap around fin missile 3-D configuration.

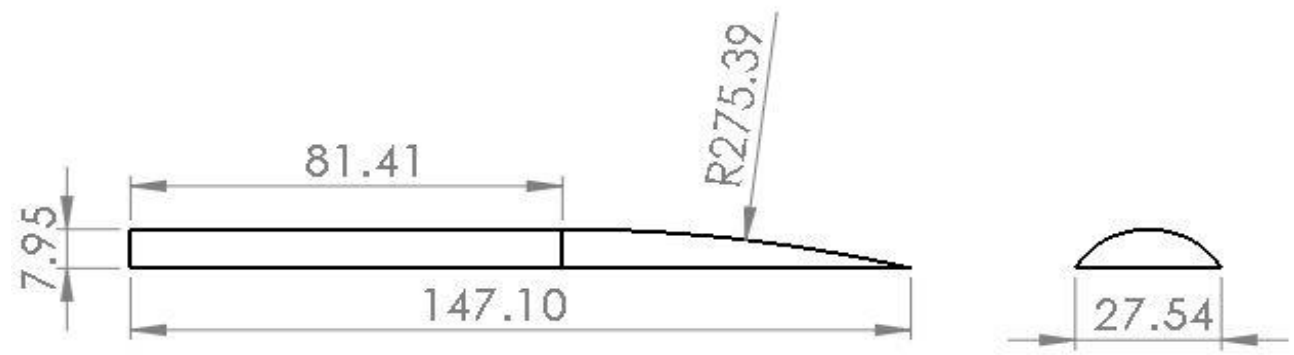

Figure 4. Geometry of the base missile, adapted semi-cylindrical body (Dimensions are in $\mathrm{mm}$ ).

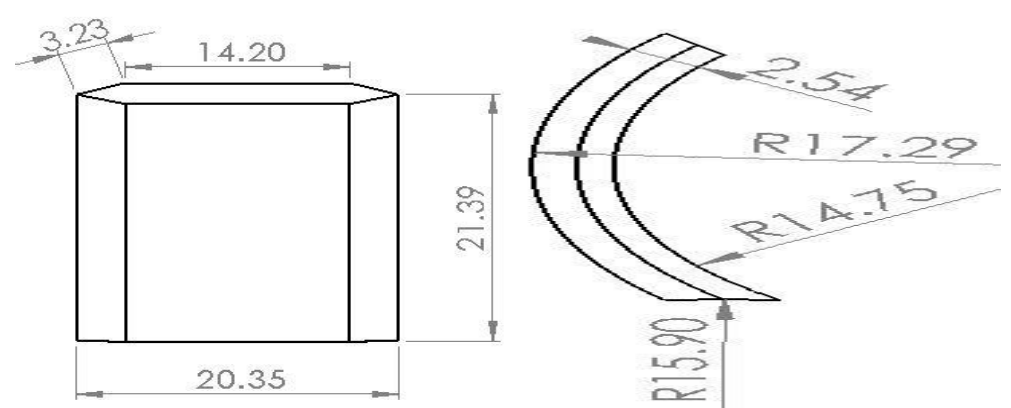

Figure 5. Wraparound fin alone geometry, (Fin dimensions are in $\mathrm{mm}$ ). 


\section{Grid Definition and the Computational Field}

The Computational domain size was same for both the planar and the wrap-around simulations. The placement of the missile body in the computational domain was similar. Both the missile models were placed such that the missile base cylinder and the missile nose meets at the origin. The inlet starts $0.3 \mathrm{~m}$ ahead of this point and the domain's outlet is placed at $0.8 \mathrm{~m}$ behind this point (Figure 6). The Inlet, Outlet and the Fairfield boundaries have been shown in Figure 7.

The mesh was completely structured for both the planar as well as the for the wrap-around model case (Figure 8). The Fins in both the cases (Planar $\&$ Wrap-around) were completely aligned to the domain geometry (Figures 9 and 10). The mesh along the missile body is aligned completely to its body and the mesh has been made of high density along the path of the flow over the missile surface, this has been done to accurately capture the shock variations along the body (Figure 11). The mesh was created using the blocking technique in ICEM $®$ CFD. Multiple O-grids were used inside the domain to create a hexadominant structured mesh. Grid orthogonality was imposed on all the elements of the domain. The missile models itself were highly structured in both the cases which helped in the accuracy of the results (Figures $12 \& 13$ ).

Multiple O-grids were used inside the domain to create a hexa-dominant structured mesh. A grid convergence study was also conducted and the mesh that was finally employed consisted of 1.4 million elements. The mean orthogonal quality of the mesh is 0.29 and the aspect ratio is within acceptable limits. A grid convergence study was also conducted using an inviscid flow simulation. For the case of planar fin model, the grid validation was performed at 1.4 million, 3.4 million, and 4.8 million cells and the results remained less than $1 \%$ deviation, hence 1.4 million cells were taken as suitable grid to save computational time. The mass flow rate in the flux reports was also computed for net mass balance remained negligible. In case of wrap-around fin model, the grid validation was performed at 1.33 million, 1.45 million, 1.47 million, and 1.92 million cells and the results remained less than $1 \%$ deviation, hence 1.45 million was adopted after the convergence test. In this case of wrap-around fin model, mass flux balance report showed negligible net results. 


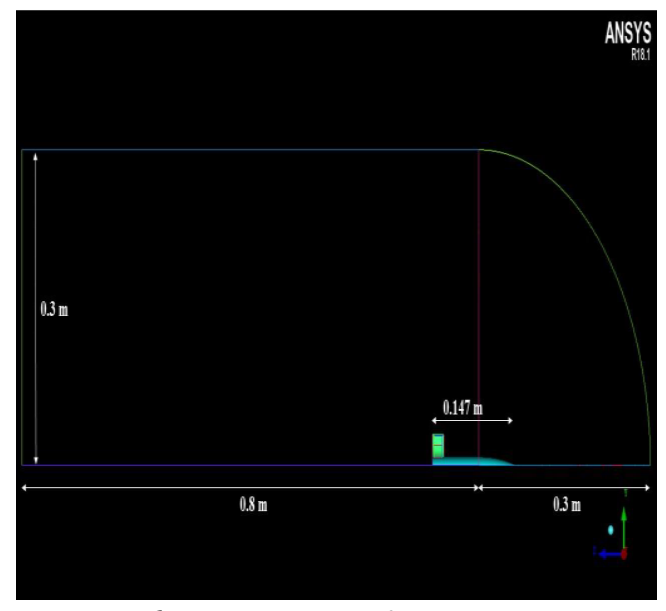

Figure 6. Geometry of Computational Domain (Front View).

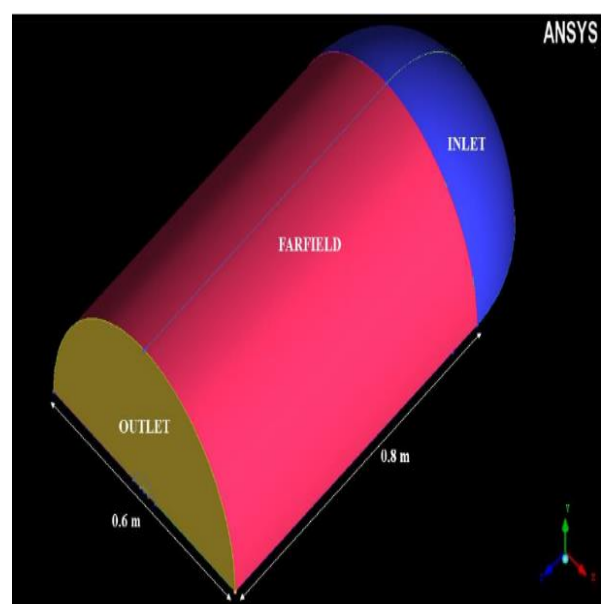

Figure 7. Isometric view of the domain used in both the cases of Planar as well as the Wraparound.

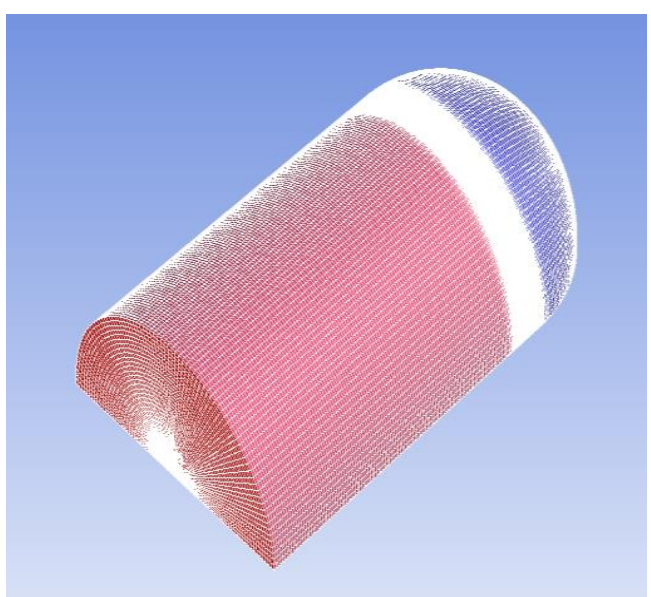

Figure 8. Completely Structured Domain Mesh of the Domains.

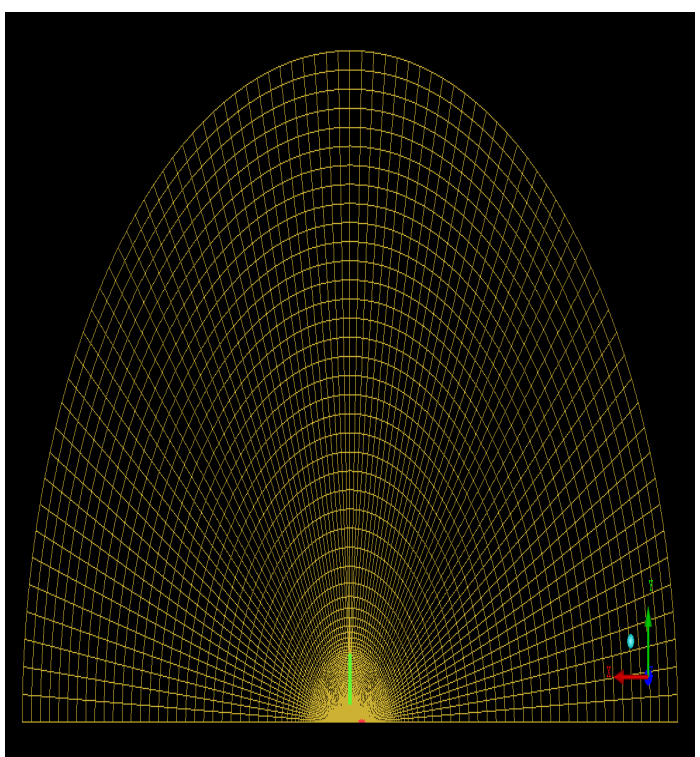

Figure 9. Sectional Rear view of the Mesh for the Planar Model Case. 


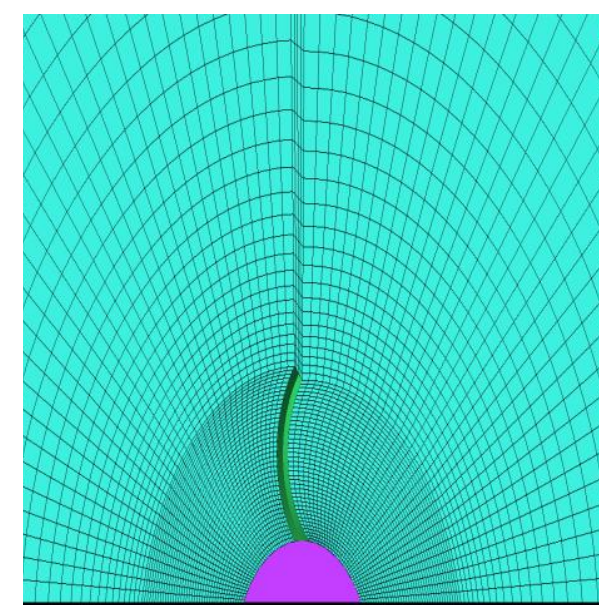

Figure 10. Sectional Rear view of the Mesh for the Wrap-around Model Case.

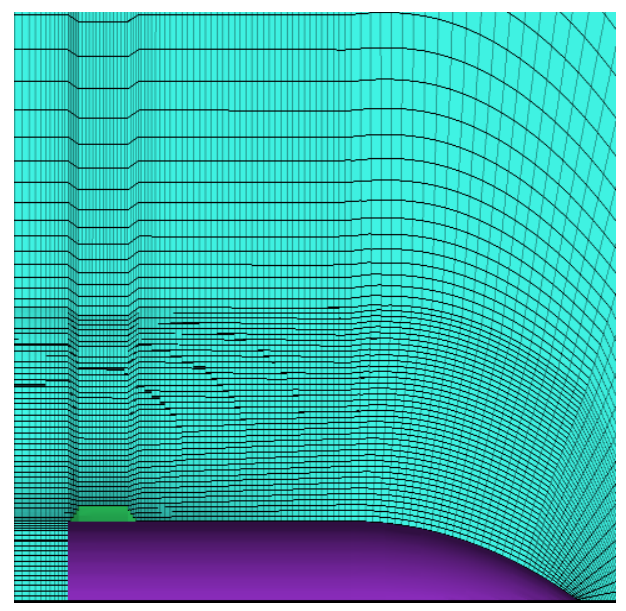

Figure 11. Sectional side view of the mesh.

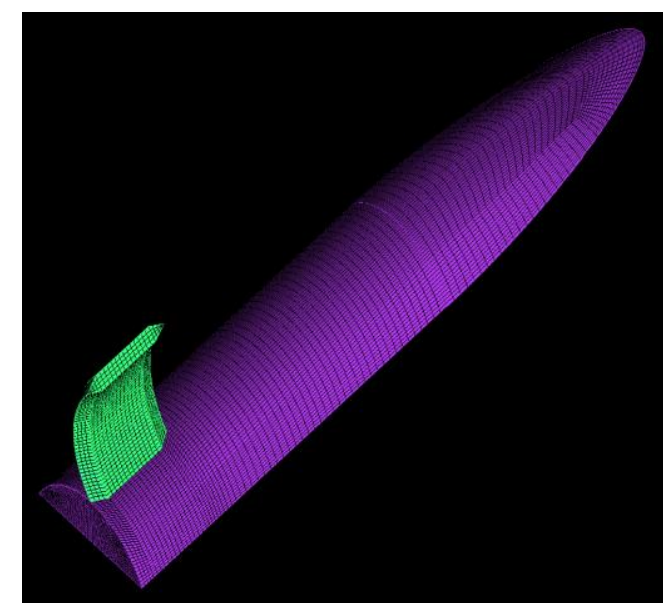

Figure 12. Meshing on the Wraparound Fin missile body.

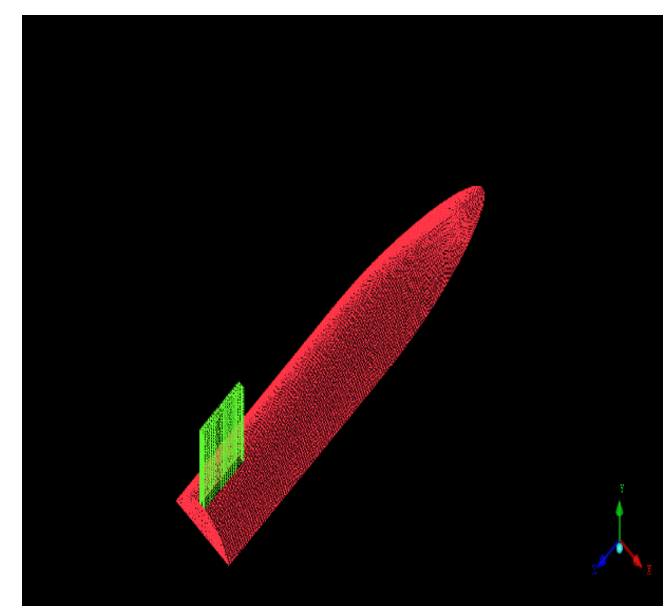

Figure 13. Meshing on the Planar Missile Body.

\section{COMPARING THE RESULTS OF BOTH COMPUTED MODELS Aerodynamic Coefficients Comparison}

The first section is dedicated to the aerodynamic coefficients such as the Drag and the Moment coefficients of the missile models. The computed results are in the Mach number range of $\sim 0.4-3.0 \mathrm{M}$ for both wrap-around and the planar cases. The Drag coefficients indicate a sharp increase in the transonic regime i.e. $\sim 0.8 \mathrm{M}-1.2 \mathrm{M}$ for both the cases of planar and the wrap-around fins. However, in the increase in Drag Coefficients is drastic in the case of wraparound fins model, nearly $51.33 \%$ as compared to $23.45 \%$ in the case of the planar fin model. The Drag coefficients at low Mach numbers $\sim 0.4 \mathrm{M}$ are almost equal to that at higher Mach numbers $\sim 3.0 \mathrm{M}$. The general trendline of Drag coefficients, indicate a pattern decrease with increase of Mach number. The planar missile model shows higher Drag values, this can be attributed to the fact 
that a blunt leading \& trailing edge fin is used rather than sharpened edges (Figure 14).

The fin alone Drag coefficients have lesser difference in comparison to the overall Drag coefficients of the missile model. the contribution of fin Drag in the overall Drag value of the model is more in the case of Planar fins as compared to the wrap-around fins. On comparison of fin alone Drag coefficients, the wrap-around fins have higher drag values as compared to their planar counter parts, which can be attributed to larger surface area for the fluid flow as compared to planar fins. On an average the wrap-around fins produce 7.12\% more drag than planar fins (Figure 15).

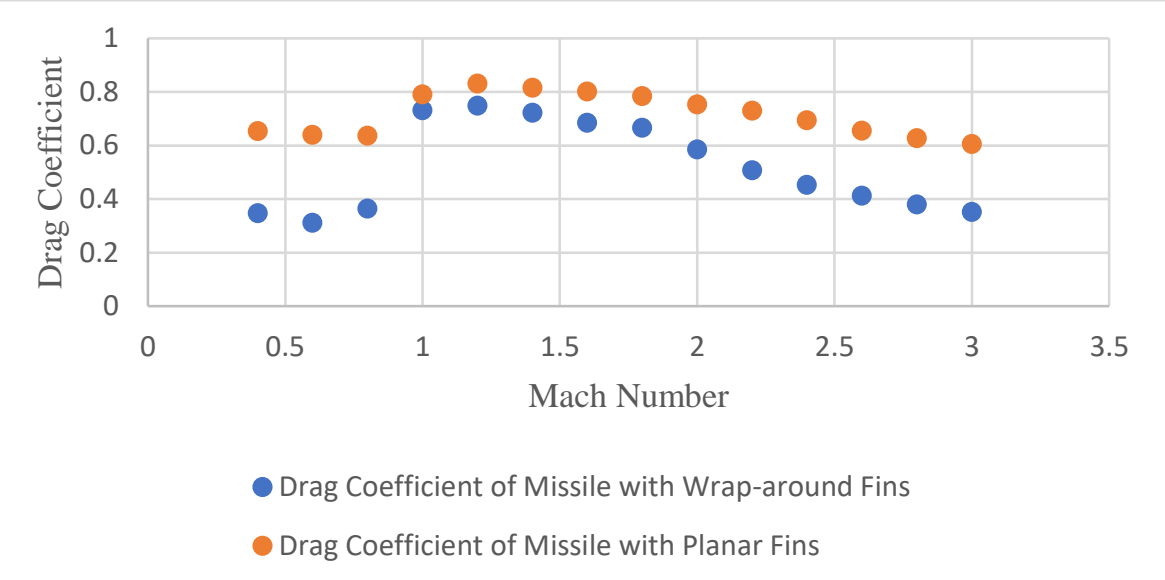

Figure 14. Drag Coefficient of the Missile Vs Mach Number Comparison of Wrap-around \& Planar Fin.

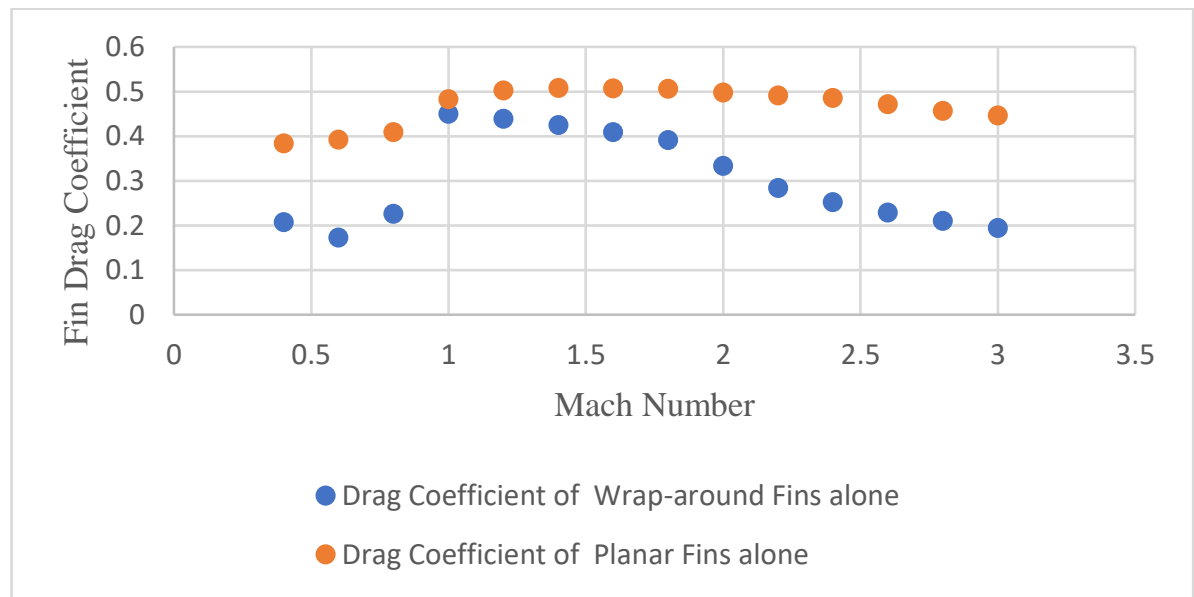

Figure 15. Fin Drag Coefficient of the Missile Vs Mach Number Comparison of Wrap-around \& Planar Fin. 
On comparison of aerodynamic coefficients of the missiles, principally with wrap-around fins, the Moment coefficient, is of major relevance. The change in the sign of the Moment coefficient has been reported between Mach number $\sim 1.2 \mathrm{M}-1.4 \mathrm{M}$ in the case of wrap-around fins. The change of sign in the Moment coefficient can be seen in the case of planar fin missile model as well however the Moment coefficient of the missile model remains nearly zero with the maximum deviation of $-0.009164(-12.90 \%)$ on the negative side at $\sim 0.8 \mathrm{M}$ and $+0.011420(+16.08 \%)$ on the positive side at $\sim 1.6 \mathrm{M}$ (Figure 16).

Considering the Moment coefficient of the fins alone, in the case of wrap-around fins, change of sign takes place at Mach number $\sim 1.2 \mathrm{M}$. In the Reference The computed rolling moment values for a single fin and for four fins (computed values multiplied by four) as suggested by Tilman et al. (1996) in the Mach range of $0.4 \mathrm{M}$ to $3.0 \mathrm{M}$ are presented in Figure 17. Considering four times, the value of fin Moment coefficient for both the wrap-around and the planar fins, the value of Moment coefficient for the planar fins remained negligible throughout the Mach number range. The flow visualizations reflecting these computed aerodynamic coefficients, are discussed in the next section.

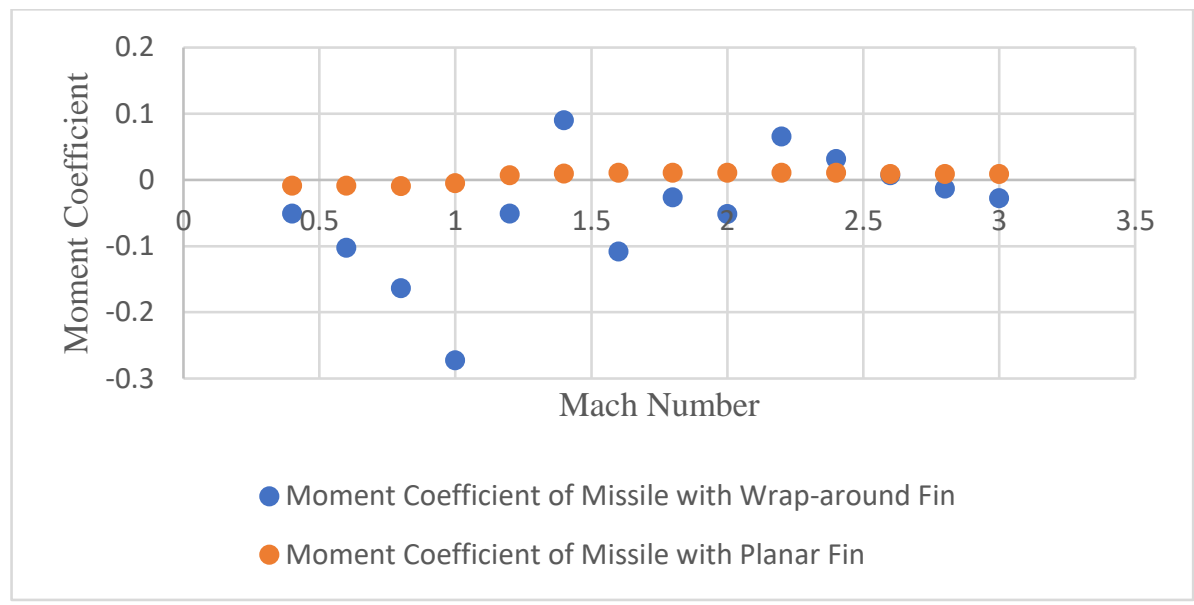

Figure 16. Moment Coefficient of the Missile Vs Mach Number Comparison of Wrap-around \& Planar Fin. 


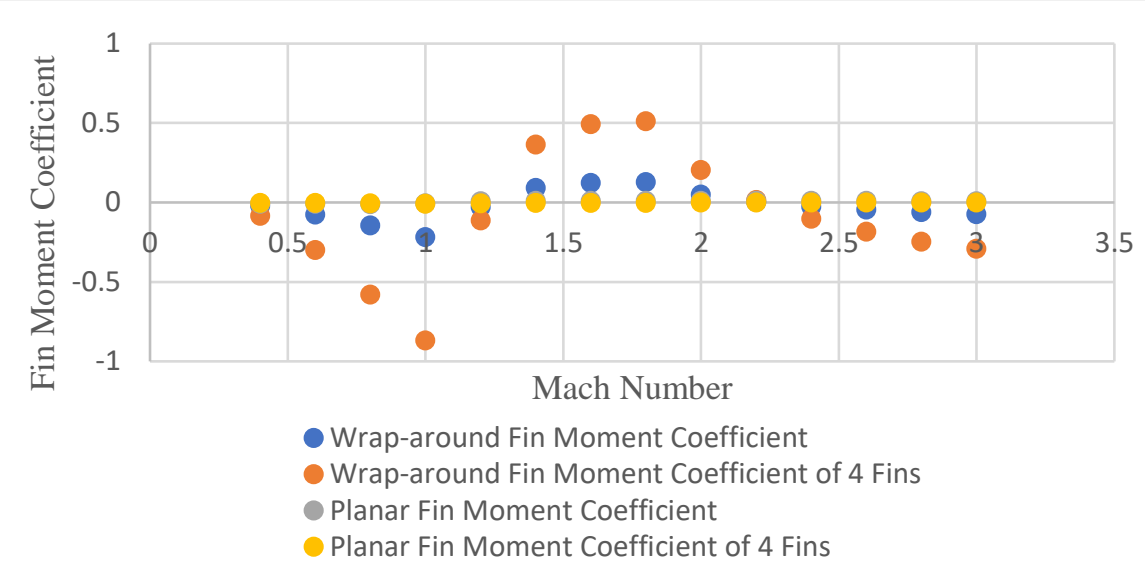

Figure 17. Fin Moment Coefficient Vs Mach Number, Comparison of Wraparound \& Planar Fin.

\section{Comparison of Computed Shock Structures, Surface Pressures \& Contours}

In the first part of this section, the flow visualizations of the turbulent computations of the planar fin missile model are presented. Figures 18 (a) (b), shows the missile surface pressures (Top View) from Mach number 0.4 to 3.0M. The figures show the static pressure contours over the missile surface and around the fin on the missile body. The oblique shock wave formed around the fin leading edge originates after Mach number $\sim 0.8 \mathrm{M}$ and the shock keeps on getting more and more prominent afterwards. The blunt leading edge of the planar fin results in significant drag, especially at the root of the fin's leading edge. The first pressure accumulation can be seen at Mach $\sim 0.8 \mathrm{M}$, a shock structure formation can be seen at the root of the fin on the missile surface which is equally distributed on both the sides of the planar fin. This shock formation is reflected in the computed values of rolling moments of the full missile body as well as the computed rolling moment values of the fin alone, which are almost negligible (Figures $16 \& 17$ in the previous section). The symmetry of the planar fins promotes zero rolling moment, and this is proved in the Figure 16. The maximum deviation of the computed rolling moment coefficient from zero is at -0.009164 at $0.8 \mathrm{M}$ and +0.011420 at $1.6 \mathrm{M}$. It is interesting to note that the overall rolling moment though negligible, still changes its sign at Mach number 1M. At Mach number $\sim 2.2 \mathrm{M}$, there is absence of pressure variations (thereby reduction in Drag) on the nose of the missile body and the oblique waves originating at the leading edge of the missile keep getting acuter. The shock waves remain symmetric and equal in all the Mach number $(1.0 \mathrm{M}-3.0 \mathrm{M})$ range, though it keeps on getting acuter with increase in the Mach number. 


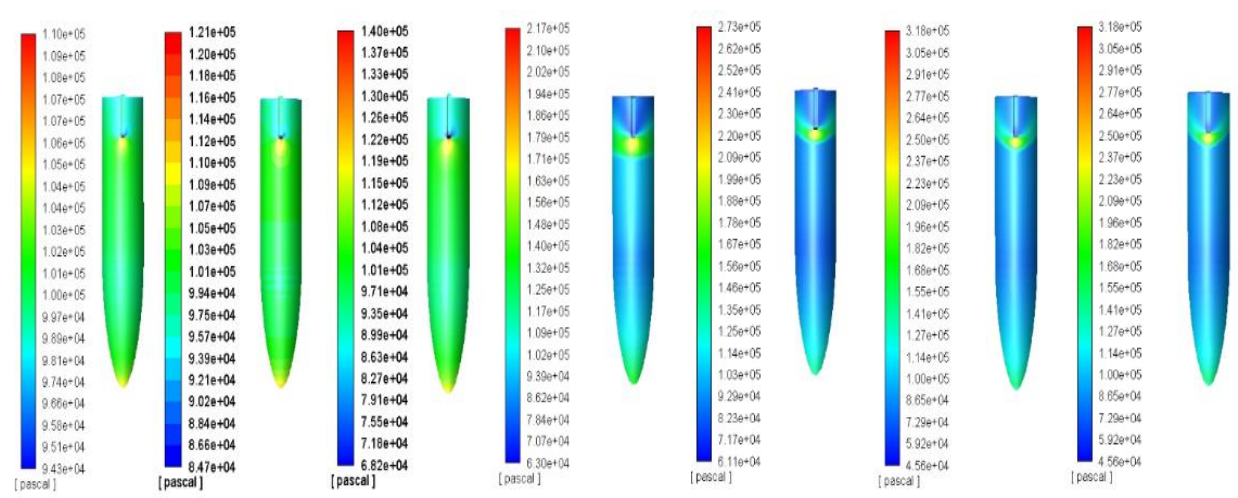

(a) $0.4-1.6 M$

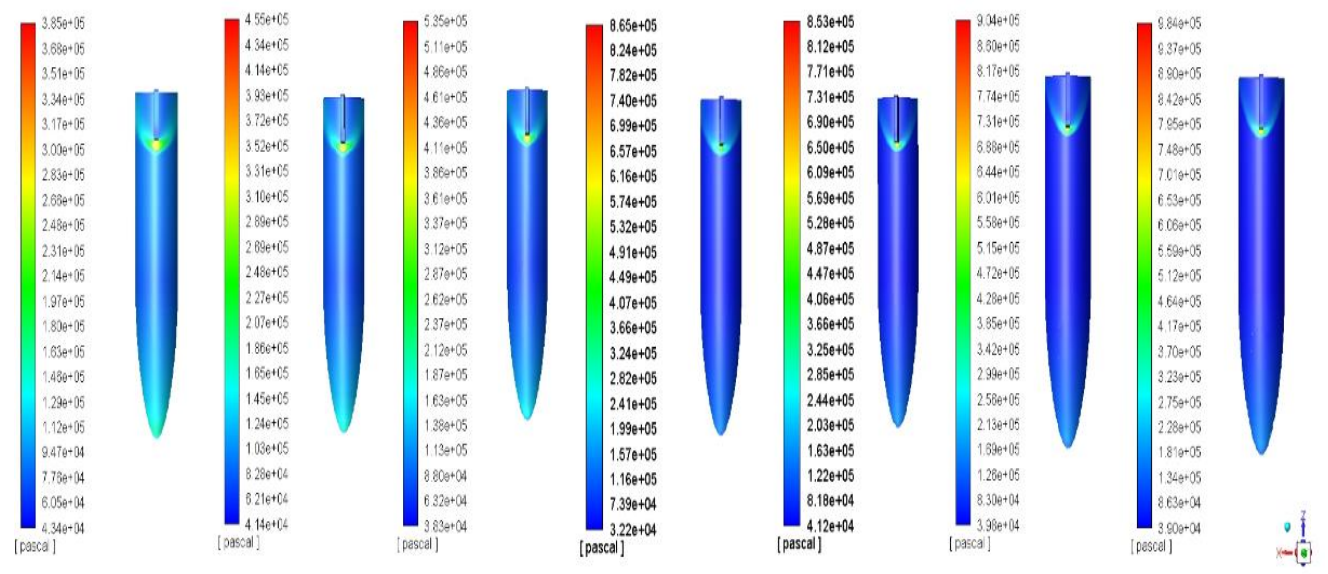

(b) $1.8-3.0 M$

Figures $18(a)(b)$. Computed Missile and fin surface pressures for Viscous turbulence calculations Mach Number Range 0.4M-3.0M.

The flow visualizations of the turbulent computations of the wraparound fin model are presented in this section. Figures 19 (a) (b) show the missile surface pressures (Top View). The first pressure accumulation can be seen at Mach 1.2, a shock structure formation can be seen at the root of the fin on the missile surface which is equal on both the sides of the leading edge. Roll reversal at Mach number of $1.2 \mathrm{M}$ can be observed, zero rolling moment value is observed (change of sign), as reported by the experimental tests conducted by Arnold Engineering Development Centre (AEDC; Dahike, 1976) at a similar Mach number of $1.2 \mathrm{M}$. The computed rolling moment values for a single fin and also for four fins (computed values multiplied by four) as suggested by Tilman et al. (1996) in the Mach range of 0.4M to 3.0M are presented in Figure 17. These computed values of rolling moment coefficients of the fins also show 
a similar trend when compared with previous computational and experimental researches, which will be covered later in the validation section of this paper. The previous CFD simulations had failed to accurately compute this critical Roll reversal Mach number near Mach number $\sim 1.0 \mathrm{M}$ (as proven experimentally) (Predicted range varied from $\sim 1.0 \mathrm{M}$ to $1.8 \mathrm{M})$ (Krishna et al. 2009). In the current computation of single wrap-around fin it was successfully determined at $\sim 1.2 \mathrm{M}$. However, the fact that there is an absence of flow interaction of adjacent fin in this case can also not be ruled out. Paek, Park, Lee, $\&$ Kwon (1999) suggested that the cause of delay of roll reversal Mach number can be attributed to the expansion and compression of waves in the fin passage. Though the possibility of second roll reversal has also been reported at Mach $\sim 4.5 \mathrm{M}$, another change of sign of rolling moment can be observed much prior to that Mach number, at Mach $\sim 2.4 \mathrm{M}$ in the current computations. However, this roll reversal can be stated for a single fin missile model only. At Mach 1.4M prominent oblique shock waves start to appear at the leading edge of the fins, and an asymmetric pressure distribution can be seen on the either sides of the fins.

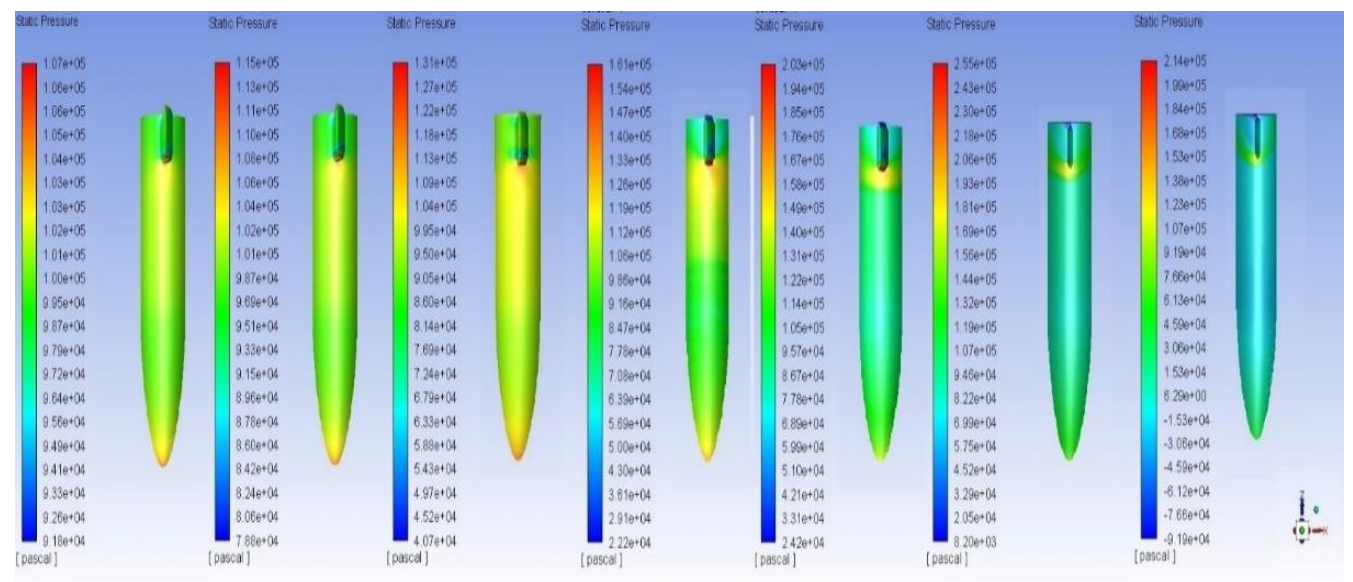

(a). Mach Range 0.4M tol.6M 


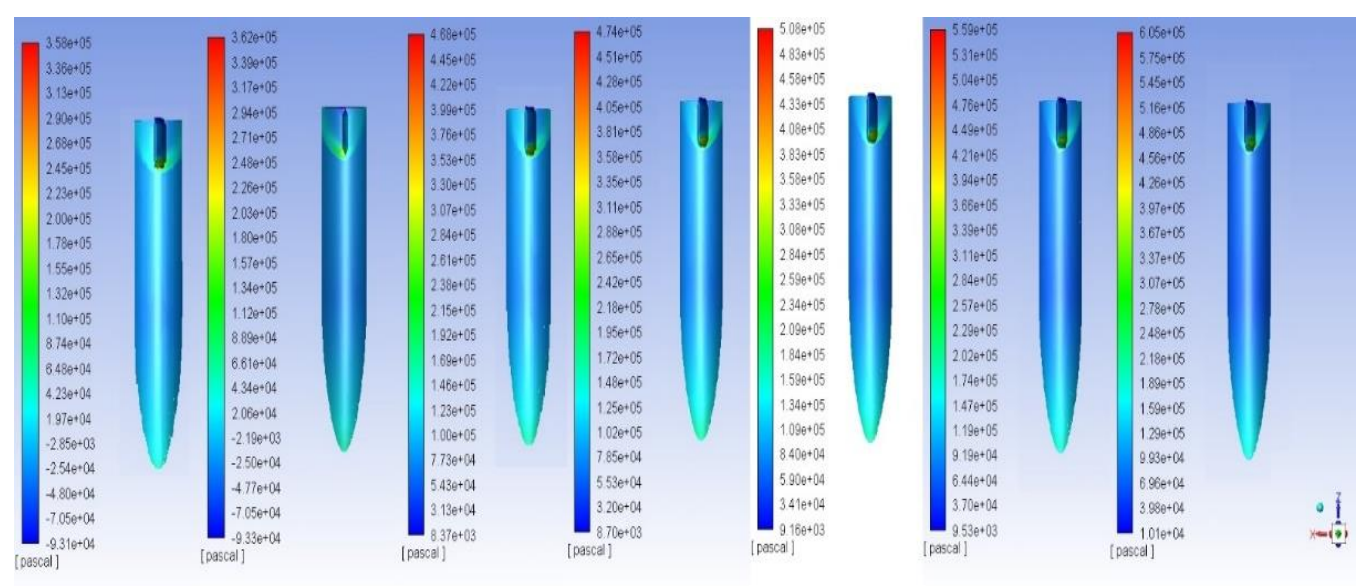

(b) Mach Range 1.8M to 3.0M

Figure $19(a)(b)$. Computed Missile and fin surface pressures for Viscous turbulence calculations.

To understand the flow phenomenon at the leading and trailing edges, a half-cut plane was selected in post processing to examine the static pressure contours (Figures 20 (a)-(b)) These images cover the complete range of flow behaviour from Mach number $0.8 \mathrm{M}$ to $1.8 \mathrm{M}$ range. The first formation of normal shock wave can be seen at Mach $\sim 1.0 \mathrm{M}$. The shocks are formed at the fin leading edge and there is a high-pressure formation at the leading edge of the fin. This flow disturbance can be seen in the values of computed drag coefficients of the model and the fin (Figures $14 \& 15$ ). This pressure accumulation which starts getting reduced at Mach number $\sim 1.6 \mathrm{M}$ and this is also reflected in the computed drag coefficients values, after which they start to decrease. Both the drag coefficients of the missile body as well as the fin alone increase drastically at Mach number $1.0 \mathrm{M}$ and the flow continues to have an increased value of drag coefficients till Mach number $\sim 1.6 \mathrm{M}$. Overall the drag coefficients of the model decrease with increase in Mach number, which is a general trend in case of aerodynamics. Initiation of weak oblique shock waves at the nose of the missile can be seen at Mach $\sim 1.2 \mathrm{M}$ and they keep getting stronger and acuter with the increase in Mach number. The pressure variations at the trailing edge of the fins start to smoothen at Mach number $\sim 1.8 \mathrm{M}$ onwards. 


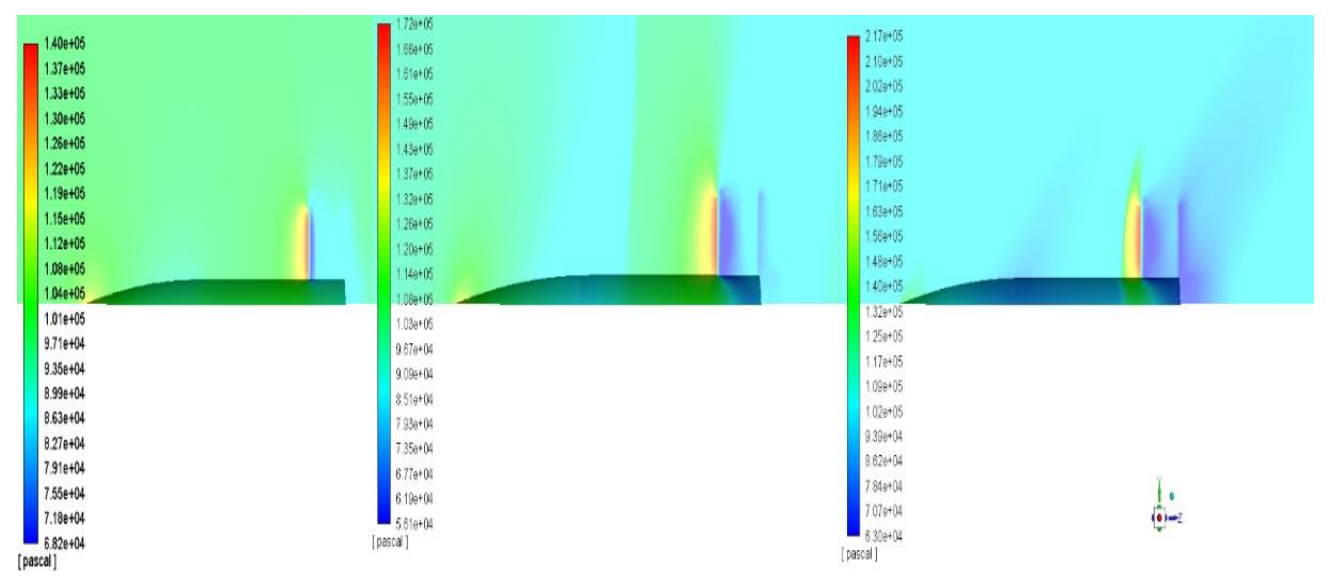

(a) $0.8-1.2 M$

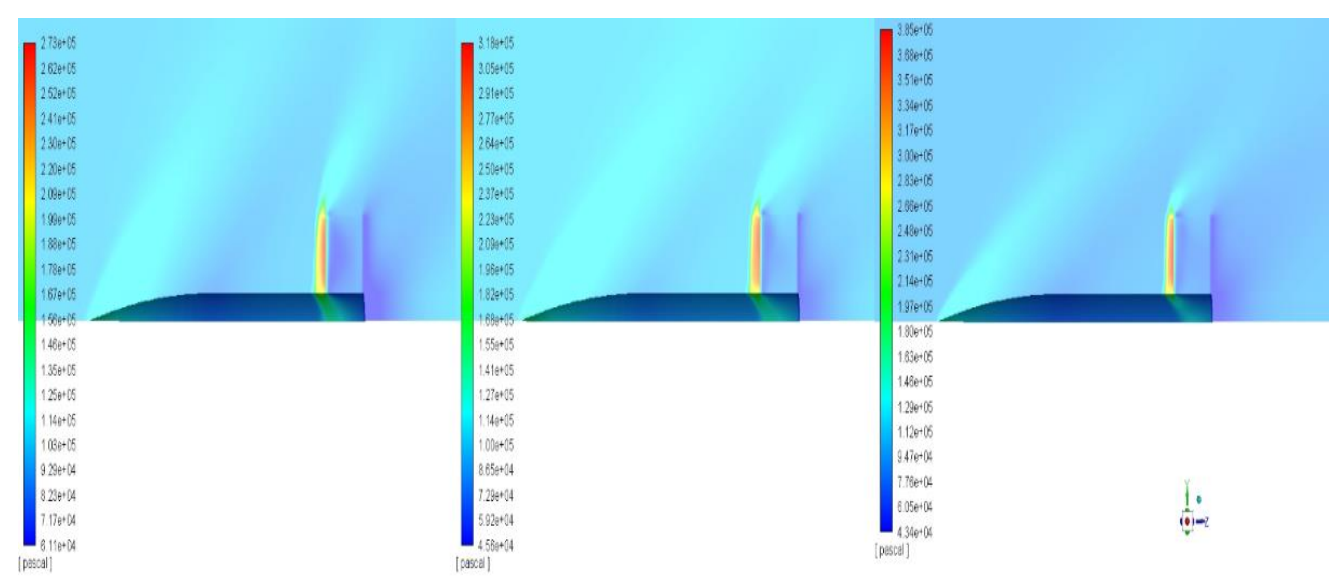

(b) $1.4-1.8 M$

Figure 20(a)-(b). Computed Mid-plane static pressures the missile model in the Mach number range 0.8-1.8M.

To examine the flow phenomenon in the case of a single wrap-around fin, due to its asymmetry (both the concave and the convex side of the fin were considered), static pressure contours were examined at the mid-plane (cut half) of the missile model in the post processing. The static pressure contours on the concave and the convex side of the missile model (in the transonic regime are shown in the Figures 21(a)\&(b). A normal shock boundary formation can be seen over the cylindrical part of the missile body at Mach 1.0M. Prominent oblique shock waves start forming at the nose of the missile and at the leading edge of the fin at Mach number $\sim 1.2 \mathrm{M}$. The flow disturbance at the trailing edge of the fin almost vanishes at Mach number $\sim 1.4 \mathrm{M}$. 
The probable explanation for reduced drag in the case of wrap-around fins as compared to the planar fins, can be attributed to the sharpened leading edge. This sharpening of the leading-edge results in formation of oblique shock waves much earlier in the case of wrap-around fins $(\sim 1.2 \mathrm{M})$ as in the case of blunt planar fins $(\sim 1.4 \mathrm{M})$.

On comparison on flow over the faces of the fins, the flow over the face of the planar fin remains smooth with little or no influence of the trailing edge. On the other hand, in the case of wrap-around fin, the trailing edge shows a little influence on the flow characteristics. The flow on the concave side of the wraparound fin is somewhat smoother than on the convex side.

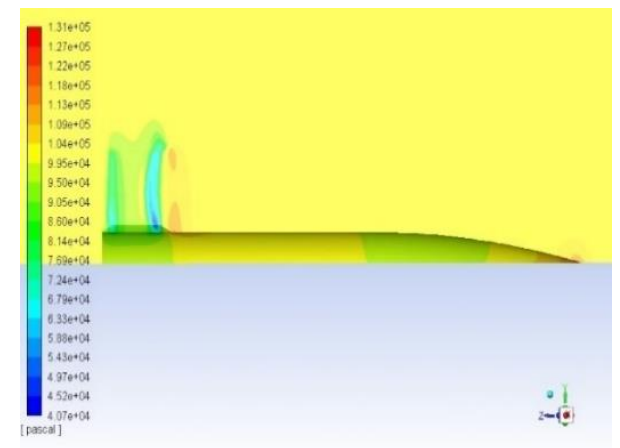

0.8 Mach Number

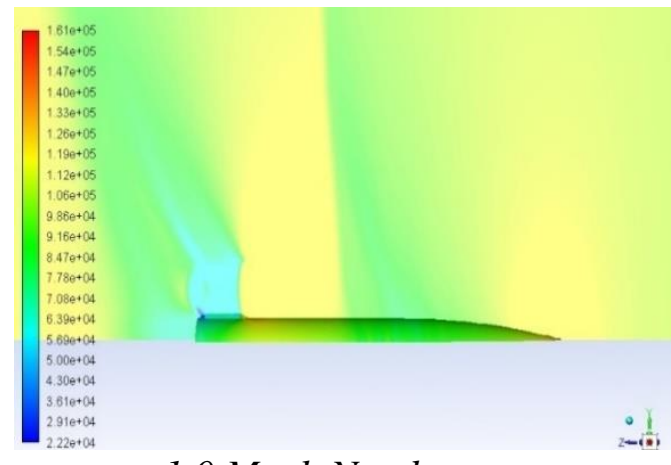

1.0 Mach Number

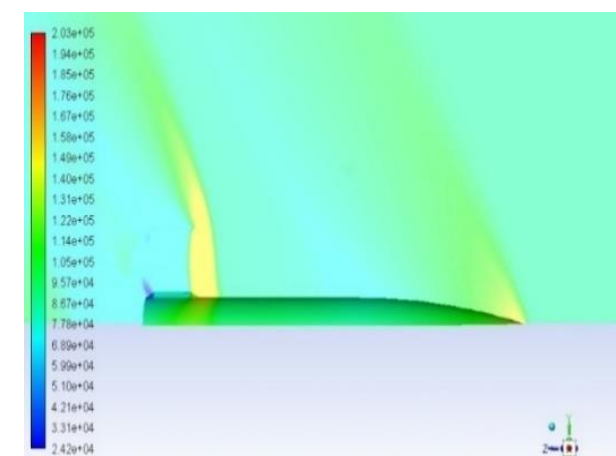

1.2 Mach Number

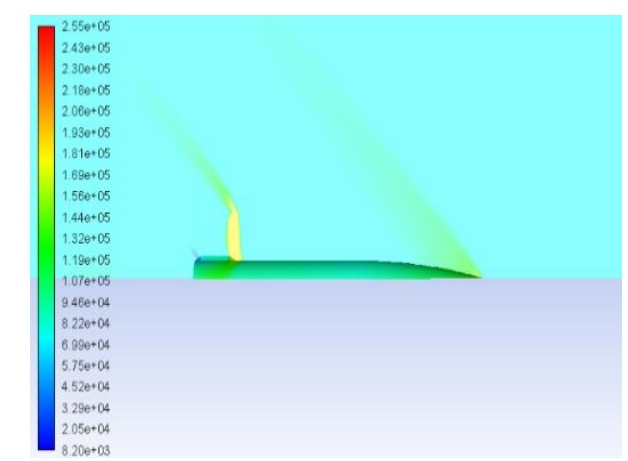

1.4 Mach Number

(a) Computed Mid-plane static pressures for concave side of the missile model in the transonic regime. 


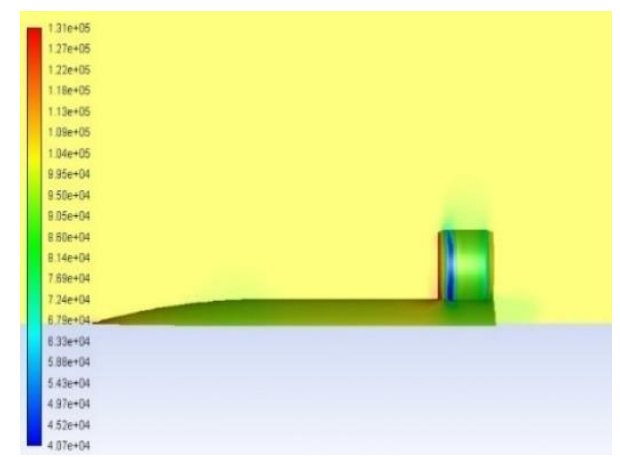

0.8 Mach Number

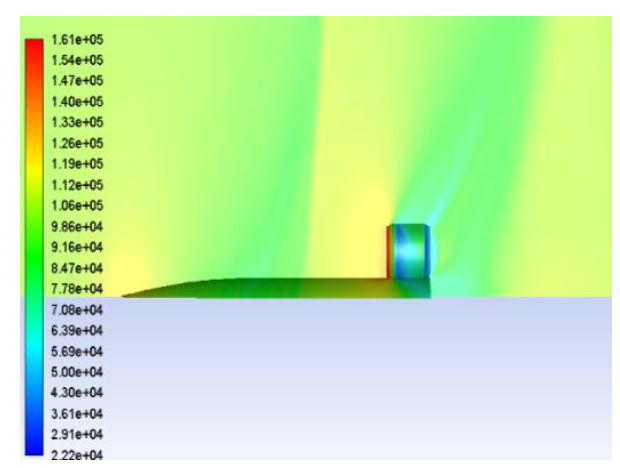

1.0 Mach Number

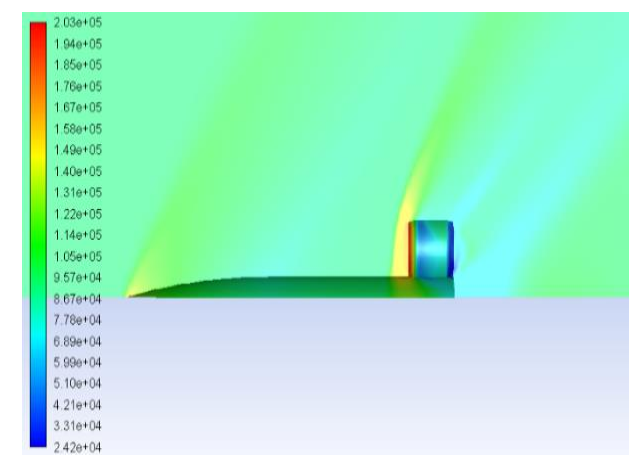

1.2 Mach Number

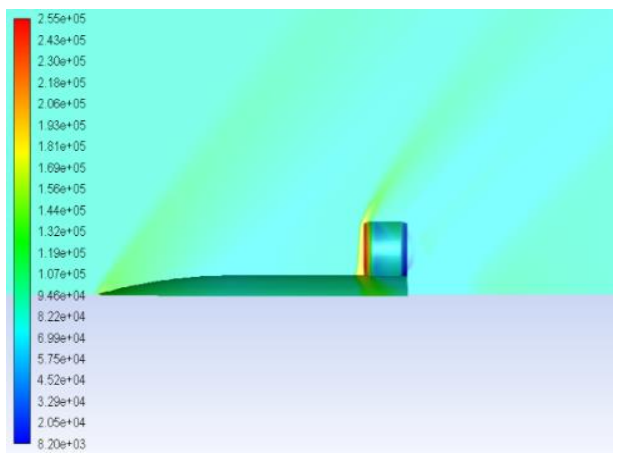

1.4 Mach Number

\section{(b) Computed Mid-plane static pressures for convex side of the missile model in the transonic regime.}

Figure 21(a)(b): Computed Mid-plane static pressures for both sides of the Single wrap-around missile model in the transonic regime.

To understand the flow phenomenon over the planar fins and to observe the flow attachment and separation around the fins, at various Mach numbers, five planes were selected. The intensity of the pressure decreases in the upward direction of the fin chord. Five chord planes have been selected to illustrate the above-mentioned flow behaviour. Five chord planes have been considered starting from fin root at $0.0 \mathrm{c}$ to the top fin tip at $1.0 \mathrm{c}$ in the in the upward direction as mentioned in the Table 1. This flow behaviour has been illustrated in the Figure 22 (a)-(b) from Mach 0.8M to Mach 1.8M, showing comparison for each chord plane in the upward Y-direction of the domain. The increase in pressure can be seen at the fin leading edge in the Figure 22(a). There is no flow disturbance at the fin trailing edge till Mach number $\sim 1.0 \mathrm{M}$.

The strength of the pressure accumulation decreases in the upward chord direction. Again, after Mach number 2.2M the pressure distribution is uniform 
aft of the trailing edge of the fin. An Interesting, phenomenon can be observed that the oblique shock wave gets acuter in the upward chord direction.

Table 1

Chordwise plane location

\begin{tabular}{|c|c|}
\hline Image & Plane Location Chord Wise \\
\hline 1 & $0.0 \mathrm{c}$ \\
\hline 2 & $0.25 \mathrm{c}$ \\
\hline 3 & $0.50 \mathrm{c}$ \\
\hline 4 & $0.75 \mathrm{c}$ \\
\hline 5 & $1.0 \mathrm{c}$ \\
\hline
\end{tabular}

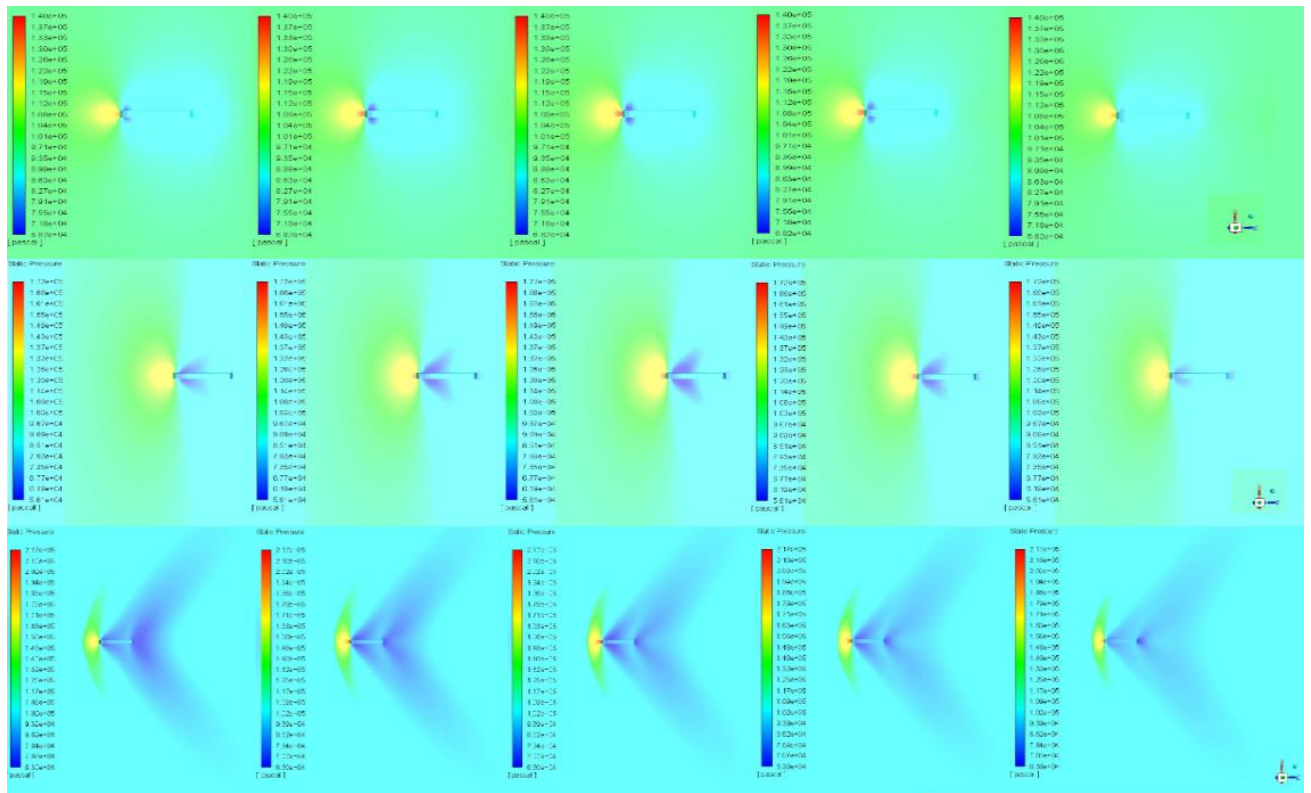

(a) $0.8-1.2 \mathrm{M}$ 


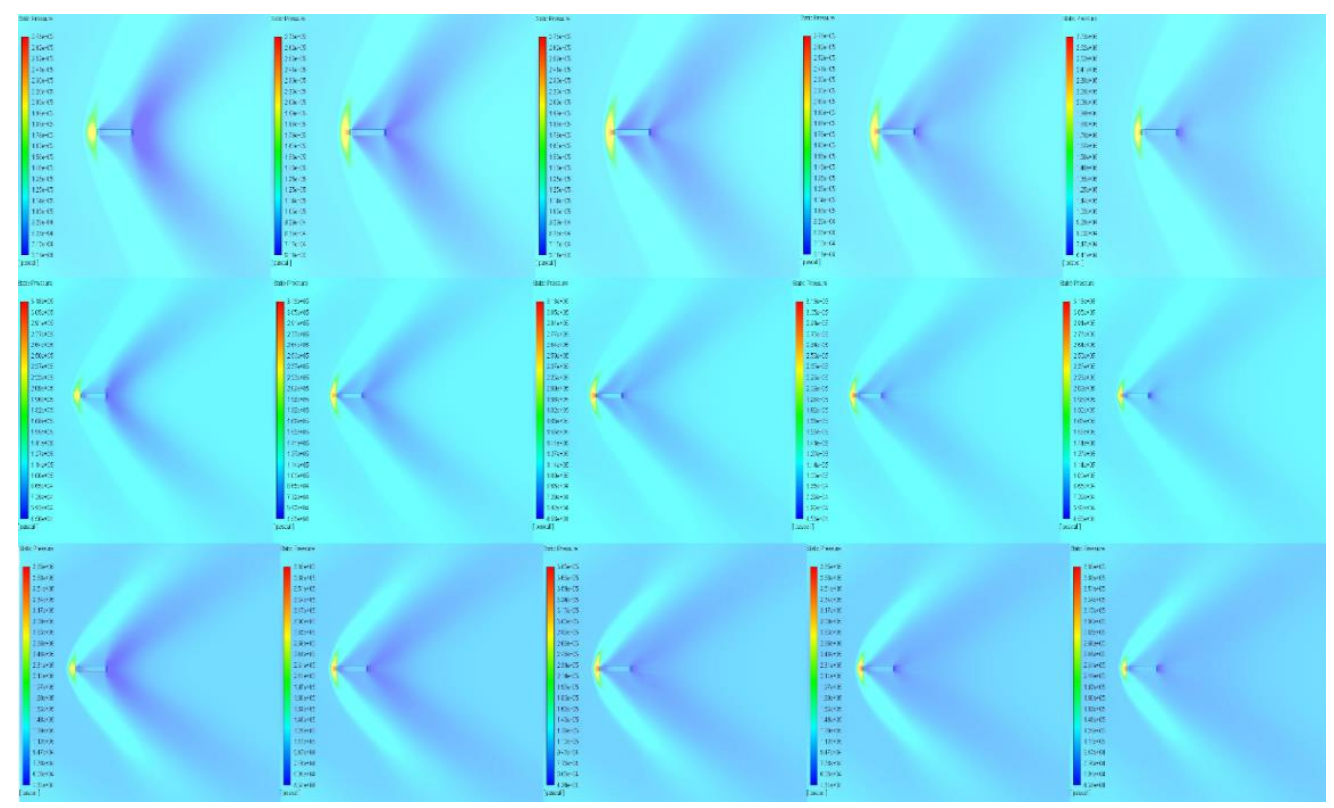

(b) $1.4-1.8 M$

Figure $22(a)-(b)$. Chordwise computed static pressure contours at five different planes from root chord (left) till the top tip of the fin (right) in the Mach number range 0.8-1.8M.

Similar five chord planes were selected to illustrate the flow behaviour around the single wrap-around fin. The five chord planes that have been considered, start from fin root at $0.0 \mathrm{c}$ to the top fin tip at $1.0 \mathrm{c}$ in the upward direction as mentioned in the Table 1 . This flow behaviour has been illustrated in the Figure 23(a)-(e) from Mach 1.0M to Mach 1.8M, showing comparison for each chord plane in the upward Y-direction of the domain. The oblique shock waves at the fin leading edge originate at Mach $1.2 \mathrm{M}$ and keep getting acute till Mach Number 1.6M and finally disappear on the leading edge of the fin around Mach 1.6M. A fin tip bleeding effect can be observed in the computational results at the root of the fin; this phenomenon is caused by the pressure difference between the two sides of the curved fins. The intensity of the pressure decreases in the upward direction of the fin chord.

This trend reflects in the computed Drag coefficient values of the missile which increase in the transonic region up to Mach $1.2 \mathrm{M}$ and then decrease with increase in the Mach number. The computed drag coefficients in the Mach number range of $0.4 \mathrm{M}$ to $3.0 \mathrm{M}$ have been shown in Figure 15. The transonic region from $0.8 \mathrm{M}$ to $1.2 \mathrm{M}$ shows abrupt changes in the drag values. These computed drag coefficient values follow the similar trends as predicted by previous experimental and computational researches and will be discussed later in the validation section of this paper. 


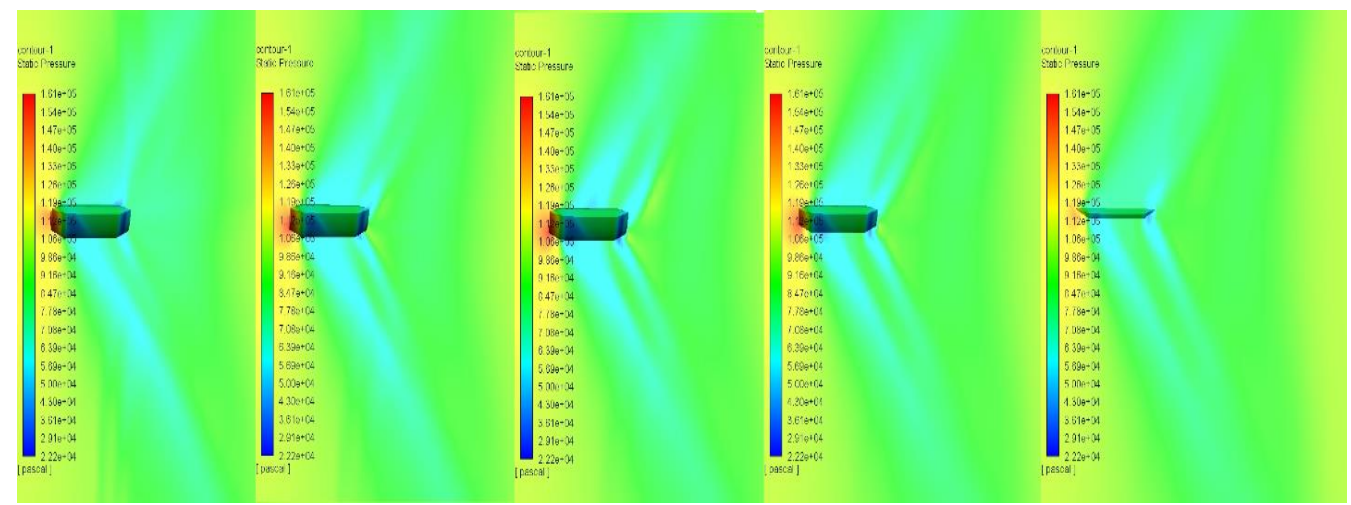

(a) 1.0 Mach Number

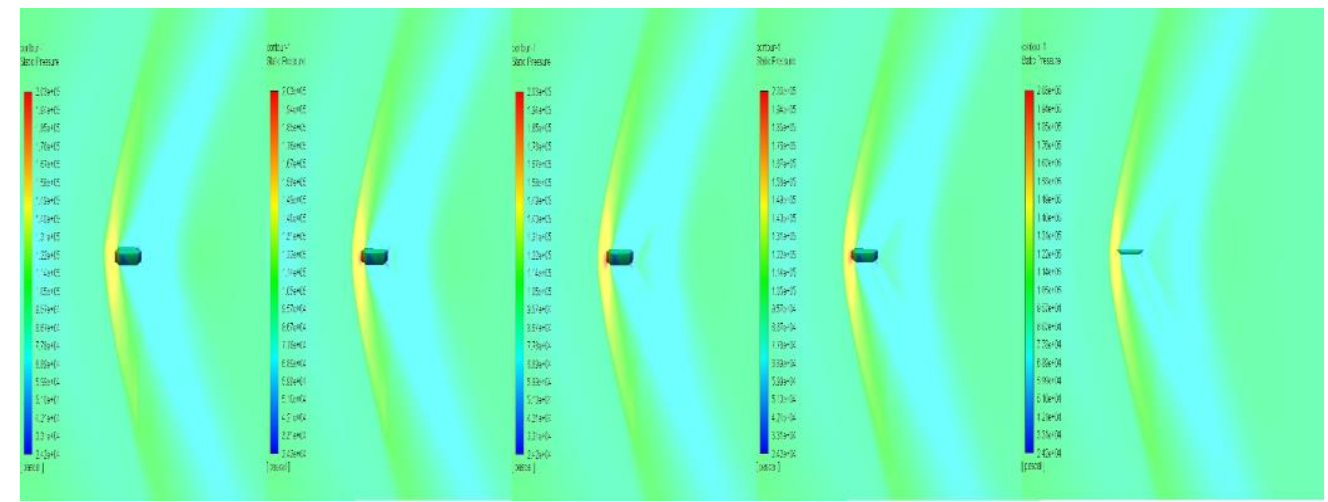

(b) 1.2 Mach Number

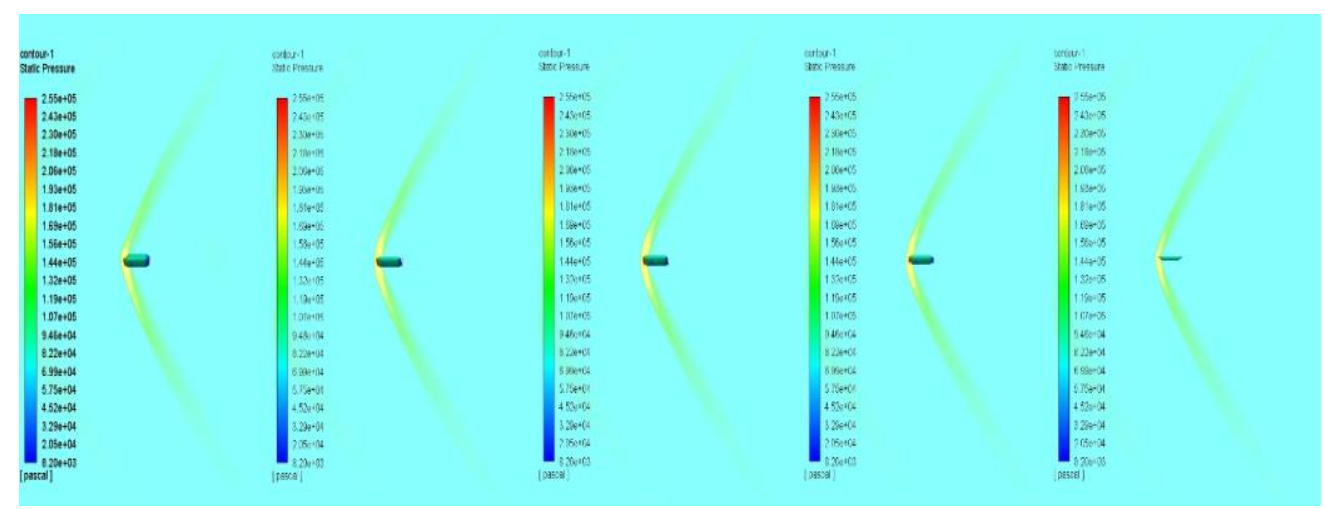

(c)1.4 Mach Number 


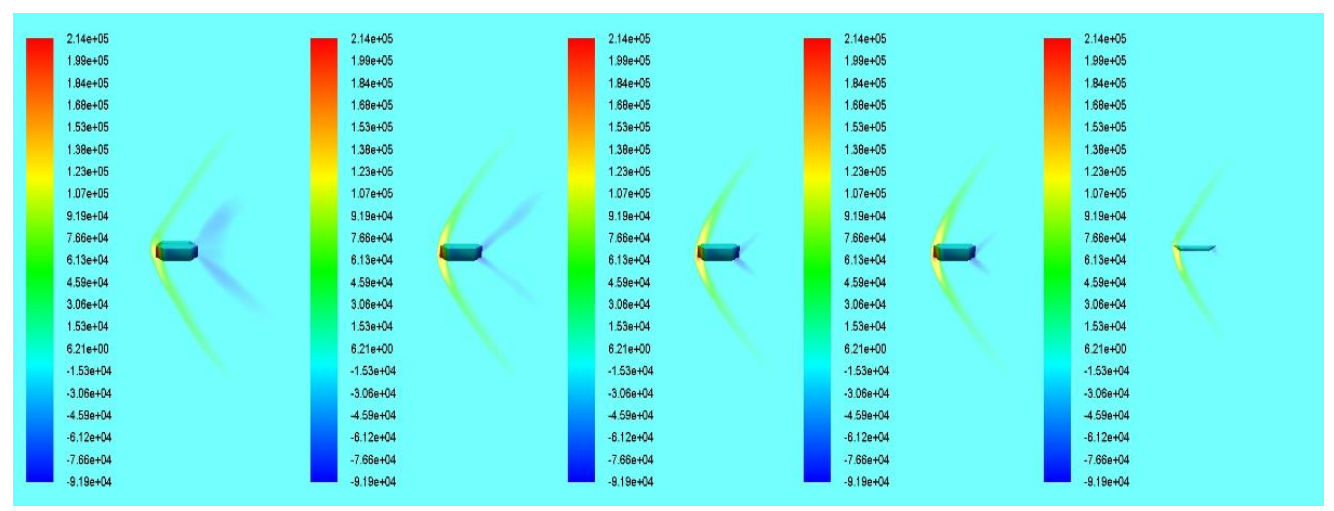

(d)1.6 Mach Number

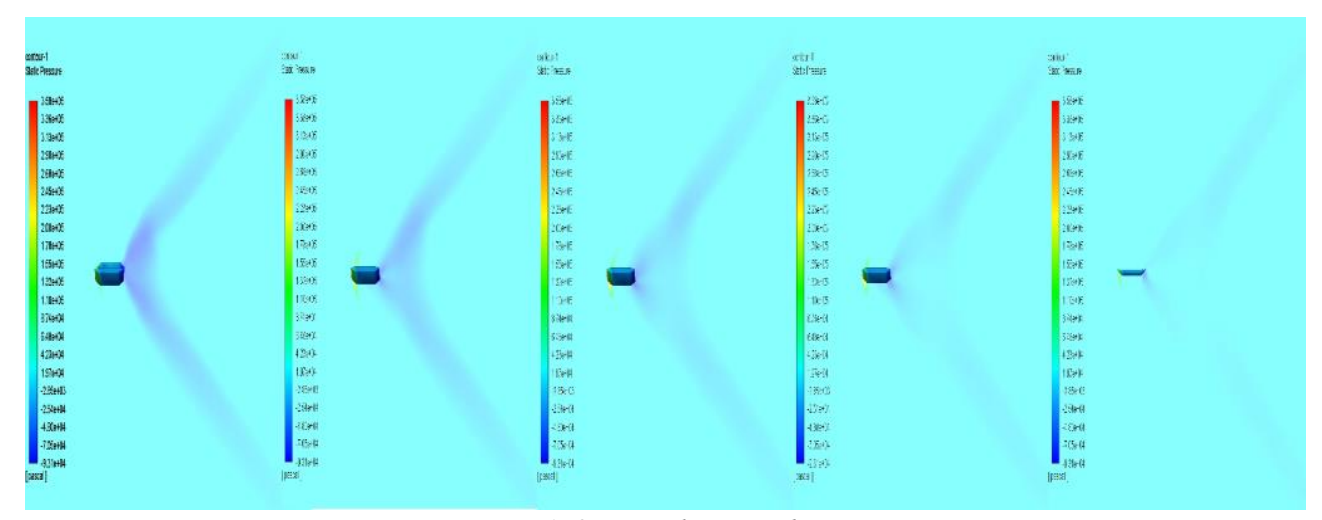

(e)1.8 Mach Number

Figure 23(a)-(e). Chordwise computed static pressure contours at five different planes from root chord (left) till the top tip of the fin (right).

Flow visualisation comparison between single planar and single wraparound fins are presented in this section. Five planes were considered in the axial direction starting from the fin leading edge and ending at the fin trailing edge. The location of these planes was at the position like Table 1, however, $0.0 \mathrm{C}$ is starting from the fin leading edge and ending at $1.0 \mathrm{C}$, at the fin trailing edge. These planes were considered in both the planar as well as wrap-around fin case. Figure 24 (a)-(f) represent the axial plane contours for the planar fins. it can be clearly seen that the pressure distribution remains equal on both the sides of the planar fin. This remained constant throughout the transonic regime as well as the complete Mach number range $\sim 0.4 \mathrm{M}$ to $30 . \mathrm{M}$, though only the transonic regime is presented in this section. This equal pressure distribution is reflected in the Moment coefficients of the planar fins, which remained negligible throughout the Mach number range $\sim 0.4 \mathrm{M}$ to $3.0 \mathrm{M}$. The blunt leading edge had maximum pressure concentration, resulting high pressure at the leading edge. The trailing edge had negligible influence on the flow aerodynamics. 


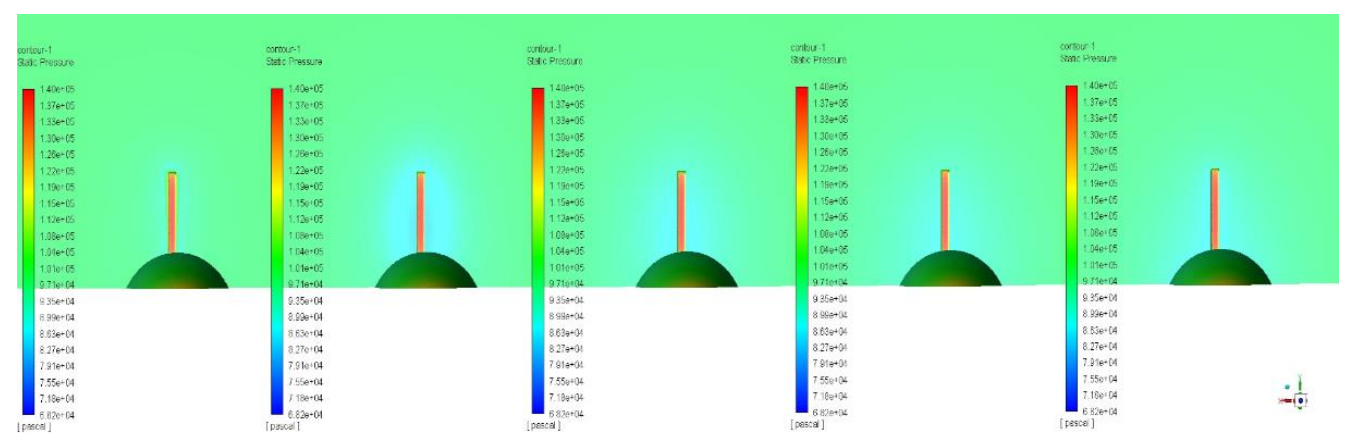

(a) $0.8 \mathrm{M}$

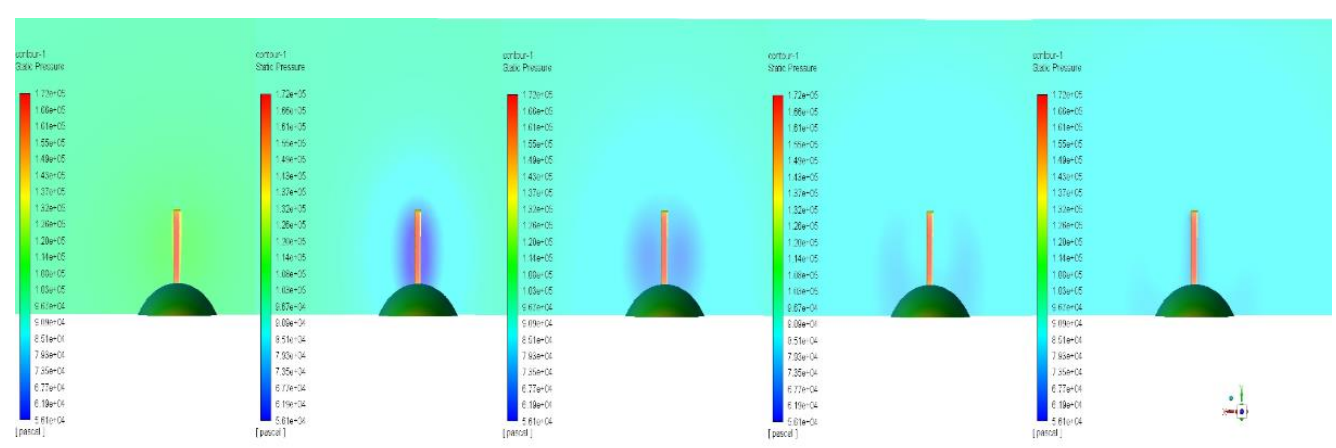

(b) $1.0 M$

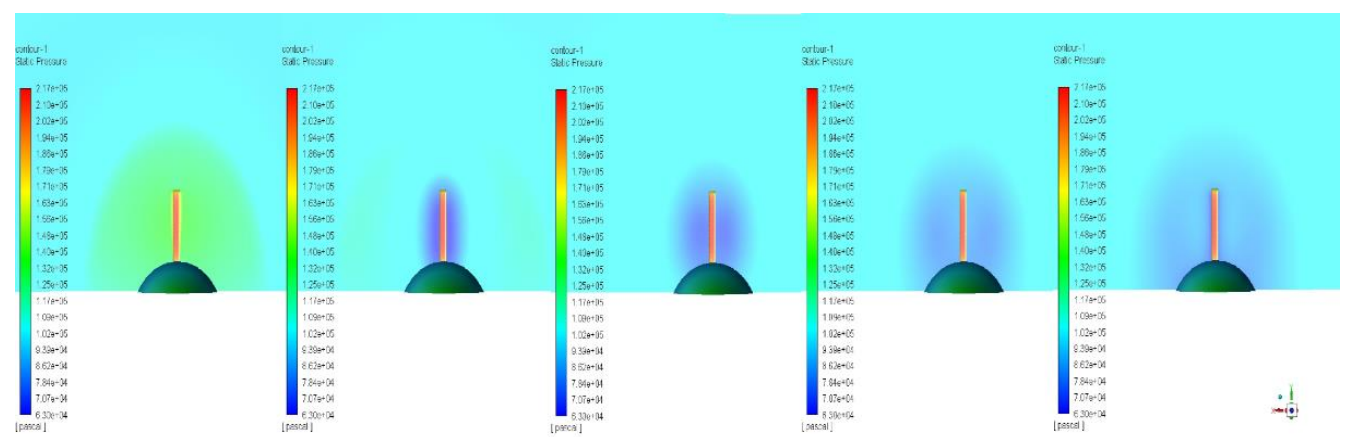

(c) $1.2 \mathrm{M}$

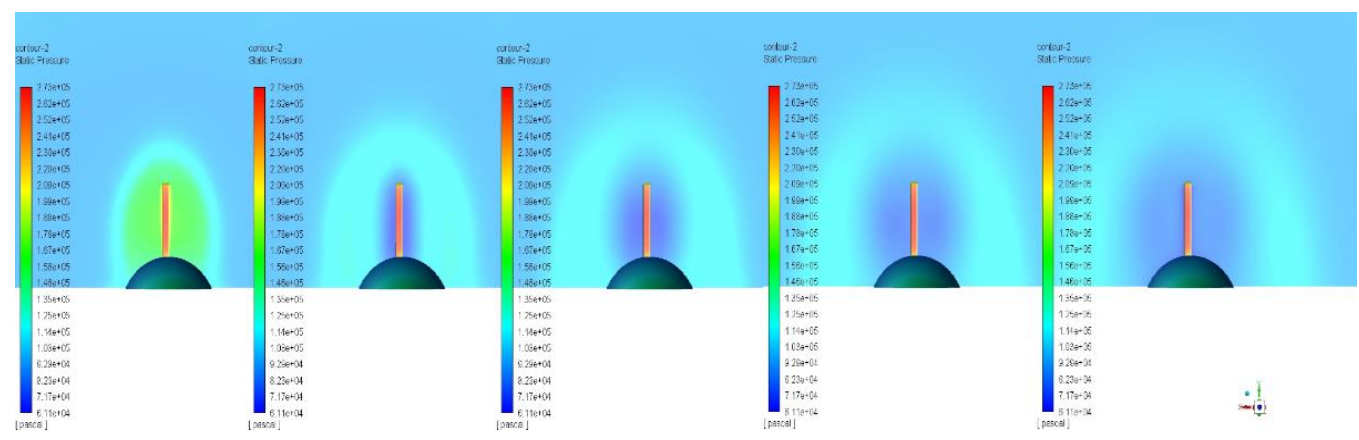

(d) $1.4 M$ 


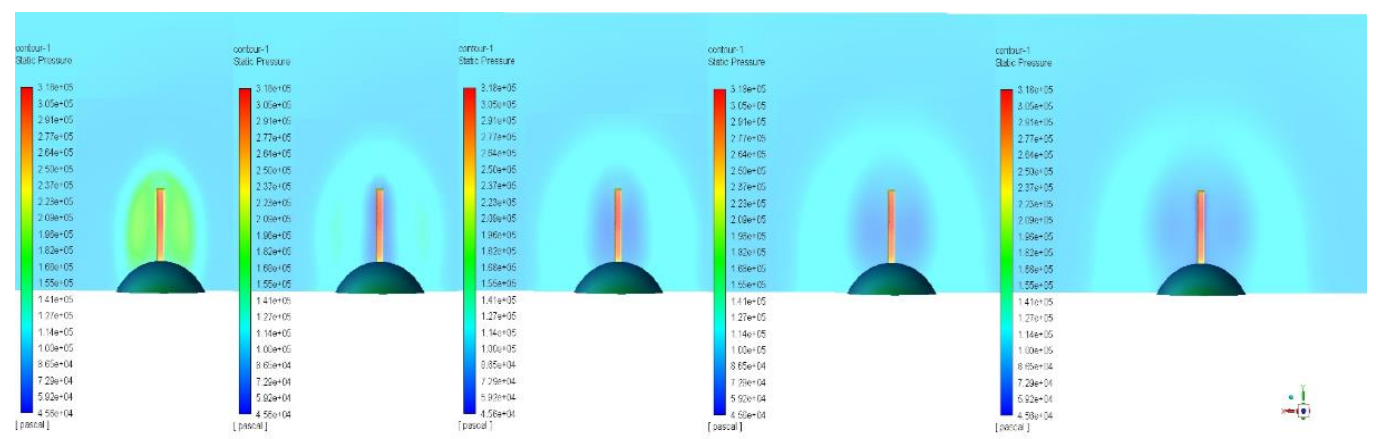

(e) $1.6 \mathrm{M}$

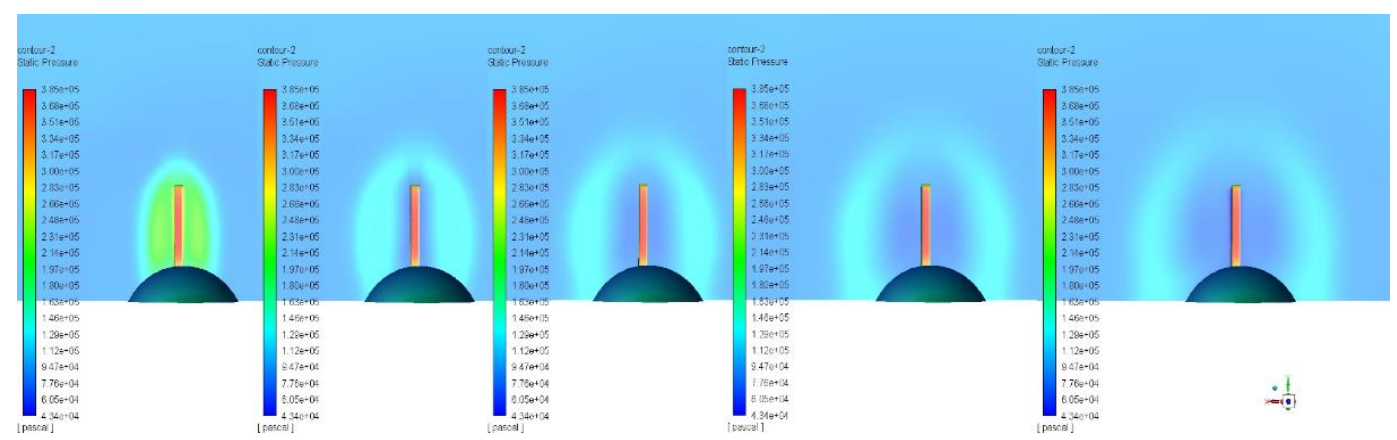

(f) $1.8 M$

Figure $24(a)-(f)$. Computed pressure contours along the single planar fin, (axially).

Similarly, pressure contours at five planes axially around the wraparound fins were also analysed. Due to the asymmetry of the wrap-around fins the flow dynamics are completely different as compared to the planar fins. The axial flow visualisations are very significant in the case of wrap-around fins as they prominently show the imbalance of pressure forces on either side of the fins, which are the reason for the induced Rolling Moment.

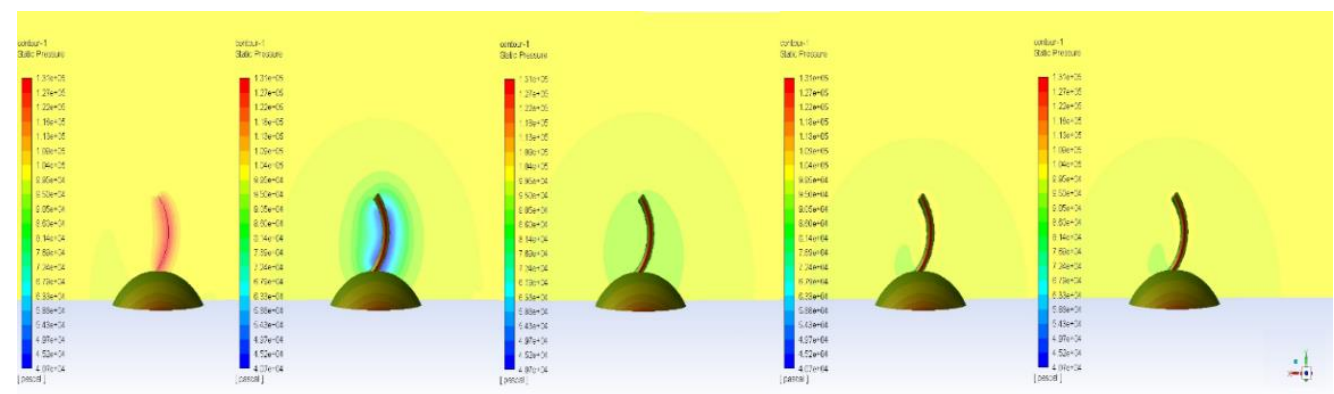

(a) $0.8 M$ 


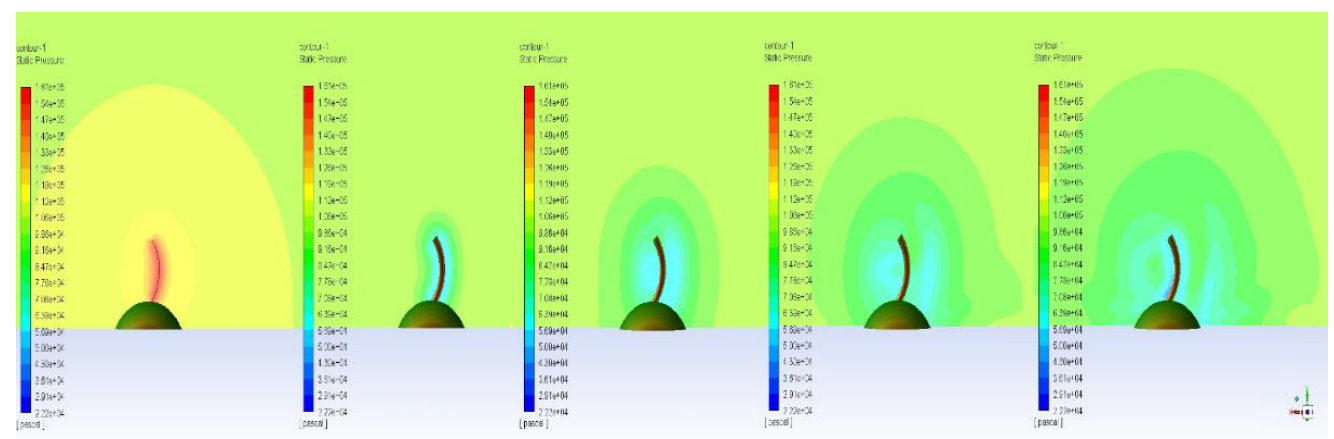

(b) $1.0 M$

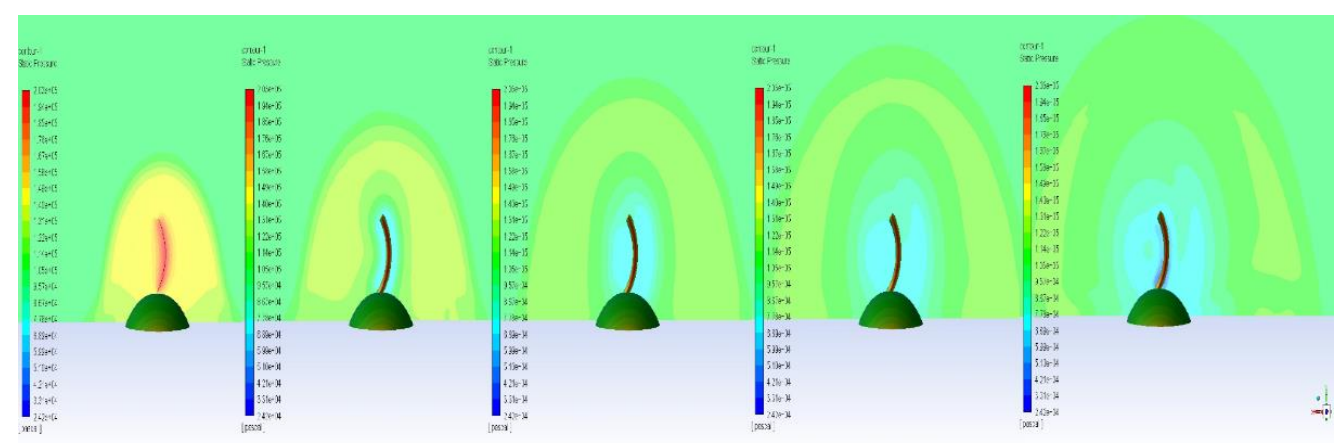

(c) $1.2 \mathrm{M}$

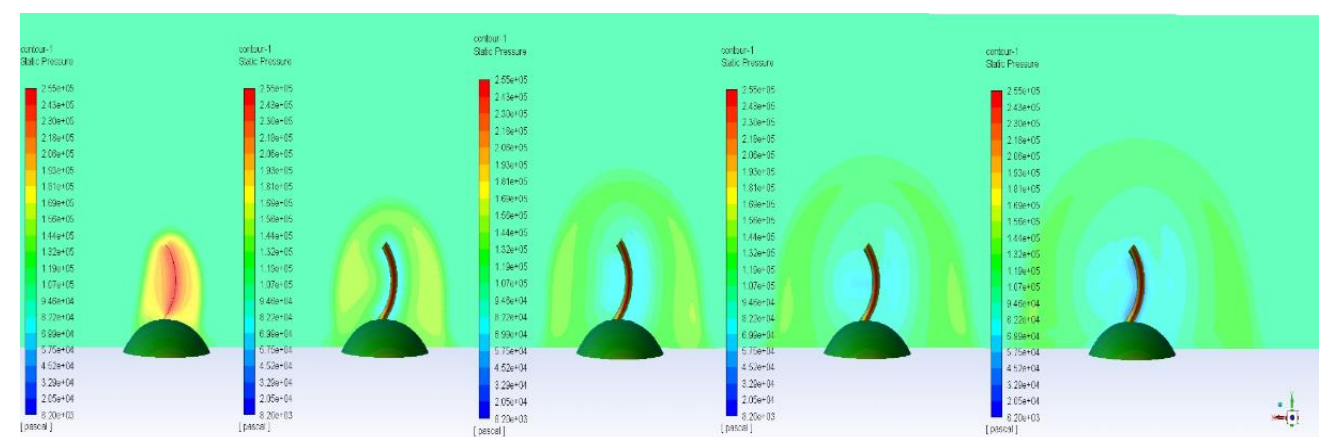

(d) $1.4 M$

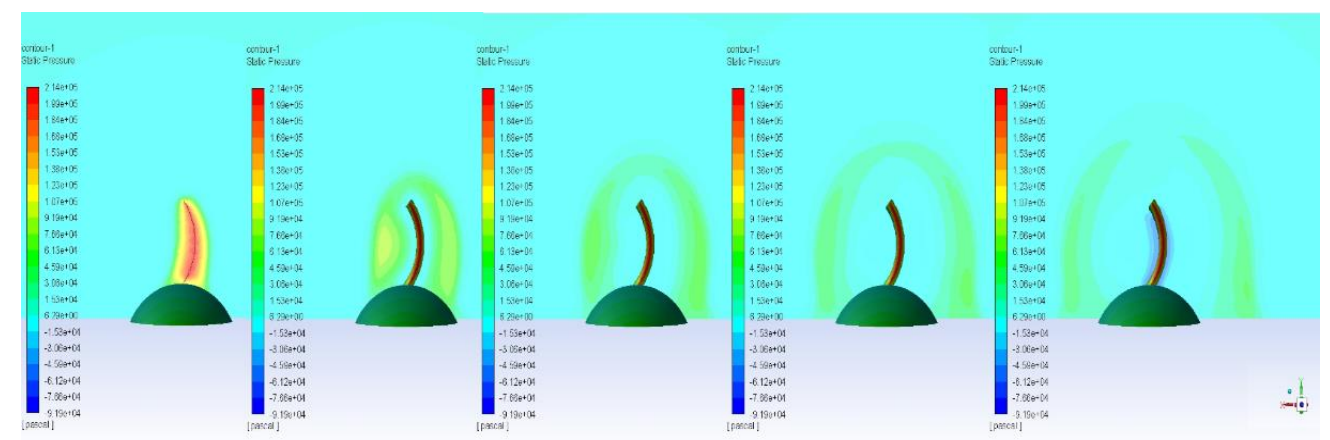

(e) $1.6 M$ 


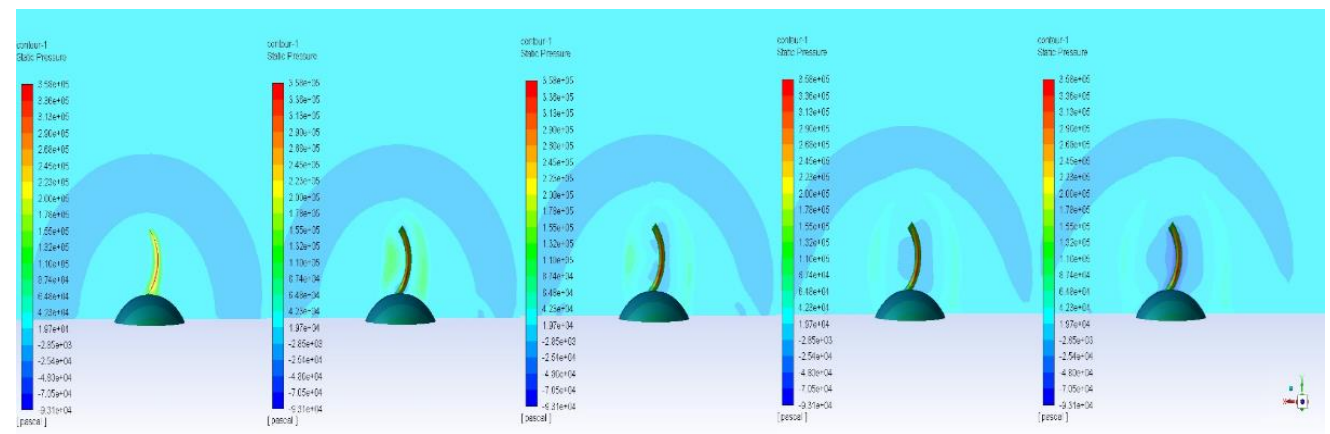

(f) $1.8 M$

Figure $25(a)-(f)$. Computed pressure contours along the single wrap-around fin, (axially).

\section{VERIFICATION \& VALIDATION}

The accuracy of the CFD simulations depends highly on the meshing and the boundary conditions. The converged solutions of these simulations of both the cases showed agreement with the previous literature consisting of both the experimental as well as CFD solutions. The obtained valued of drag coefficients and rolling moment coefficients were compared for a single fin as well as a full body missile with all four fins. For the computation of drag coefficients the reference area $A_{R e f}=\pi R^{2}$ and the reference length is $L_{R e f}=$ $R$, where $R$ is the radius $(\sim 7.95 \mathrm{~mm})$, this has been taken as in accordance with references (Li et al., 2015; Paek et al., 1999; Dahike \& Wayne, 1976).

For the single planar fin model, for the validation purpose, the predicted drag coefficient values were compared with the previous experimental studies. (DeSpirito, Vaughn, \& Washington 2003; Abatew, Duckerschein, \& Hathaway 2000) The predicted values of drag coefficients of planar fins are well within the acceptable range (Figure 26). The Drag coefficients showed similar trends of that of the earlier experimental counterparts. The increase in the value of Drag coefficients can be attributed to the fact that blunt fins have been used in the present simulations and majority of the planar studies had sharpened leading and trailing edges.

For the validation of single wrap-around fin model, the predicted drag coefficient values were compared with the experimental counterparts (Abate \& Hathaway, 1994; Abate \& Winchenbach, 1991; Swenson, Abate \& Whyte, 1994; Vitale et al., 1992; Wichenbach, Buff, Whyter, \& Hathaway, 1986). See Figure 27. The computed values of the Drag Coefficients agree significantly with almost whole of the Mach number range data i.e. from $0.4 \mathrm{M}$ to $3.0 \mathrm{M}$. 


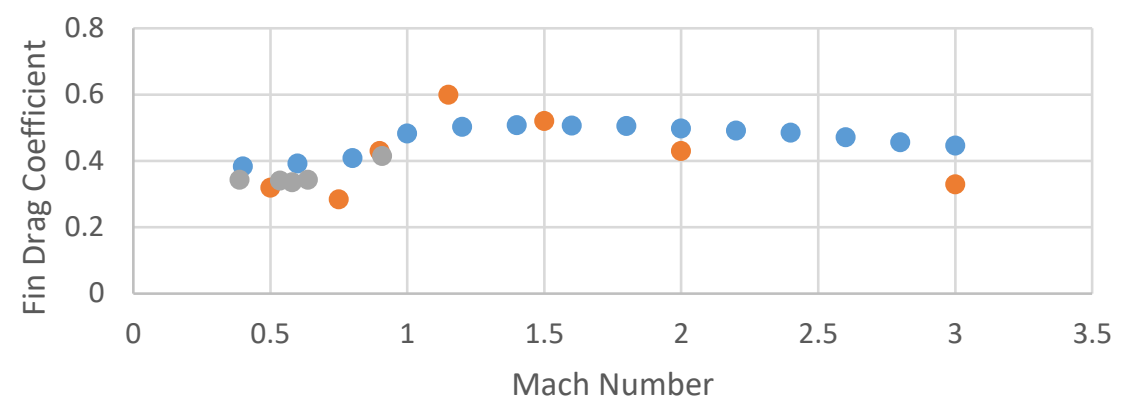

- Present Computed Fin Drag Coefficient @ DeSpirito, J 2003

- Gregg, Abate L2000.

Figure 26. Present (planar)Fin Drag Coefficient Vs Mach Number compared with previous Experimental Drag Coefficient values.

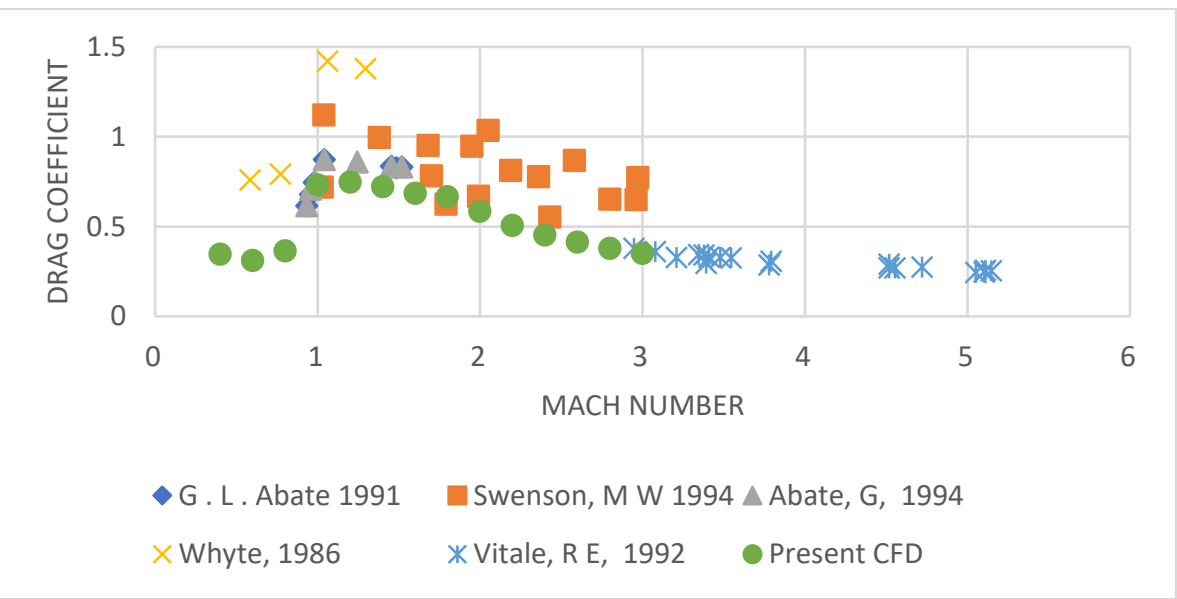

Figure 27. Wrap-around fin Drag Coefficients (Experimental) from previous studies Vs Mach Number compared with present CFD Results.

\section{CONCLUSIONS}

Though this paper compares a generic planar single fin in the computations, which is having blunt leading and trailing edges, a sharpened edged planar fin might help in better comparison with the wrap-around fin. However, for basic comparison of the flow characteristics between the two fins, the current models provided decent results. The aerodynamic characteristics of both the single fin models are predicted satisfactorily and are good enough for the preliminary design of missile fins.

The limitation of the current single fin planar and wrap-around models is that the simulations of these models are limited to zero-degree angle of attack. The computed Lift coefficients values from these models might not be useful. 
However, such models are perfect for understanding the flow aerodynamics around the various fin geometries, and, useful for the prediction of Drag as well as Rolling moment coefficients at zero-degree angle of attack.

The flow characteristic comparison has been done for both the planar as well as the wrap-around fin in the complete Mach number range of $\sim 0.4 \mathrm{M}$ to 3.0M. This Mach number range covers the subsonic, transonic (high relevance), and the supersonic regime.

The results show that the symmetric nature of the planar fins does not have self-induced rolling moments, or side forces. Change in the sign of Rolling Moment can be seen in both the planar and the wrap-around fins however the effect of Rolling Moment remains negligible in the case of planar fins. On comparing the aerodynamic coefficients of a planar fin and a wrap-around fin of similar projected planform area, the Drag coefficient has minimal effect and the Rolling coefficient has a significant effect. In the future, aerodynamics of new fin geometries, or modified fin geometries can be analysed using a similar methodology, of using a single fin mounted on the semi-cylindrical missile model. 


\section{REFERENCES}

Abate, G., Duckerschein, R., \& Hathaway, W. (2000). Subsonic /transonic free flight-tests of a generic missile with grid fin. https://doi.org/10.2514/ 6.2000-937

Abate, G., \& Hathaway, W. (1994). Aerodynamic test and analysis of wrap around fins with base cavities. https://doi.org/doi:10.2514/6.1994-51

Abate, G., \& Winchenbach, G. (1991). Aerodynamics of missiles with slotted fin configurations. https://doi.org/10.2514/6.1991-676

ANSYS. (2001a). Chapter 10. Modeling turbulence. Retreived from http://www.afs.enea.it/fluent/Public/Fluent-Doc/PDF/chp22.pdf

ANSYS. (2001b). Chapter 24. Using the solver. Retreived from http://www.afs.enea.it/fluent/Public/Fluent-Doc/PDF/chp22.pdf

Bagheri, A., Pasandidehfard, M., \& Tavakoli Sabour, S. A. (2018). Numerical investigation of aerodynamic effects of opposite wrap-around fins at supersonic speeds. https://doi.org/10.1177/0954406218784317

Baldwin, B. S., \& Lomax, H. (n.d.). Thin-layer approximation and algebraic model for separated turbulentflows. https://doi.org/10.2514/6.1978-257

Dahike, C. W. (1976). The aerodynamic characteristics of wrap-around fins at mach numbers of 0.3 to 3.0. US Army Missile Research, Development and Engineering Laboratory. Redstone Arsenal, Alabama. Retrieved from https://apps.dtic.mil/dtic/tr/fulltext/u2/a036715.pdf

DeSpirito, J., Vaughn, M., \& Washington, W. (2003). Subsonic flow cfd investigation of canard-controlled missile with planar and grid fins. https://doi.org/10.2514/6.2003-27

Eidell, M., Nance, R., McGowan, G., Carpenter, J., \& Moore, F. (2012). Computational investigation of roll damping for missile configurations. https://doi.org/10.2514/6.2012-2904

Huffman, R., Tilmann, C., Buter, T., \& Bowersox, R. (1996). Experimental investigation of the flow structure in the vicinity of a single wrap-around fin at mach 2.9. https://doi.org/10.2514/6.1996-2450

Krishna, R., Surit, R., Kushari, A., \& Ghosh, A. (2009). Anomalies in the flow over projectile with wrap-around fins. https://doi.org/10.14429/ dsj.59.1546

Li, M., Abbas, L. K., \& Rui, X. (2015). The simulation of wraparound fins. Aerodynamic Characteristics, 10, 247-52.

Liu, C. (2014). Computational fluid dynamics: A practical approach. https://doi.org/10.1007/s13398-014-0173-7.2

Liu, X., Tang, S. J., \& Guo, J. (2013). Comparison of the wrap-around fins and the planar fins in aerodynamic parameter. https://doi.org/10.4028/ www.scientific.net/ amm.444-445.347

Lucero, E. F. (1976). Subsonic stability and control characteristics of configurations incorporating wrap-around surfaces. https://doi.org/10.2514/3.57135

Mandić, S. (2006). Analysis of the rolling moment coefficients of a rockets with wraparound fins. Scientific-Technical Review, LVI(2): 30-37. 
Murman, S. M. (2007). Reduced-frequency approach for calculating dynamic derivatives. https://doi.org/10.2514/1.15758

Paek, S.-.K., Park, T.-S., Bae, J.-S., Lee, I., \& Kwon, J. H. (1999). Computation of roll moment for projectile with wraparound fins using euler equation. https://doi.org/10.2514/2.3432

Sharma, N., \& Kumar, R. (2019). A ready reckoner of CFD for wrap-around fins. https://doi.org/10.13111/2066-8201.2019.11.2.13

Sutherland, W. (2011). LII. The viscosity of gases and molecular force. https://doi.org/10.1080/14786449308620508

Swenson, M. W., Abate, G. L., \& Whyte, R. H. (1994). Aerodynamic test and analysis of wrap-around fins at supersonic mach numbers utilizing design of experiments. https://doi.org/10.2514/6.1994-200

Tanrõkulu, O., Onen, C., \& Gokhan, T. (2000). Nonlinear yaw - pitch - roll coupling of unguided missles with wraparpund fins. https://doi.org/ $10.2514 / 2.3644$

Tilmann, C. P., Buter, T. A., \& Bowersox, R. D. W. (1998). Characterization of the flow field near a wrap-around fin at mach 2.8. https://doi.org/ $10.2514 / 2.2406$

Tilmann, C. P., Huffman, Jr, R., Buter, T. A., \& Bowersox, R. D. W. (1996). Characterization of the flow structure in the vicinity of a wrap-around fin at supersonic speeds. https://doi.org/10.2514/6.1996-190

Tilmann, C. P., Huffman, Jr, R., Buter, T. A., \& Bowersox, R. D. W. (1997). Experimental investigation of the flow structure near a single wraparound fin. https://doi.org/10.2514/2.3303

Vitale, R. E., Abate, G. L., Winchenbach, G., \& Riner, W. (1992). Aerodynamic test and analysis of a missile configuration with curved fins. https://doi.org/10.2514/6.1992-4495

Washington, W. (1983). Experimental investigation of rolling moment for a body-wing-tail missile configuration with wrap around wings and straight tails at supersonic speeds. https://doi.org/doi:10.2514/6.19832081

Wichenbach, G. L., Buff, R. S., Whyte, R. H., \& Hathaway, W. H. (1986). Subsonic and transonic aerodynamics of a wraparound fin configuration. https://doi.org/10.2514/3.20156

Zhang, G. Q., Ji, L. C., Xu, Y., \& Schlüter, J. (2015). Parametric study of different fins for a rocket at supersonic flow. https://doi.org/10.1177/ 0954406215590642 